\title{
Occurrence climatology of equatorial plasma bubbles (EPBs) using optical observations over Kolhapur, India during solar cycle-24
}

\author{
Onkar B. Gurav ${ }^{1,2}$, Rupesh N. Ghodpage*,3, Parashram T. Patil ${ }^{3}$, \\ Sripathi Samireddipalle ${ }^{1}$, Ashok K. Sharma ${ }^{4}$, Alok K. Taori ${ }^{5}$ and Dadaso J. Shetti ${ }^{6}$ \\ (1) Indian Institute of Geomagnetism, Navi Mumbai, India \\ (2) Department of Physics, Bharati Vidyapeeth (Deemed to be University), Yashwantrao Mohite College of Arts, Science \\ and Commerce, Pune, India \\ (3) Medium Frequency Radar, Indian Institute of Geomagnetism, Shivaji University Campus, Kolhapur, India \\ (4) School of Physics, Shri Mata Vaisno Devi University, Katra Kakryal, Katra, J\&K, India \\ (5) Earth \& Climate Science Area, National Remote Sensing Centre, Hyderabad, India \\ (6) Department of Physics, Smt. Kasturbai Walchand College, Sangli, India
}

Article history: received December 29, 2018; accepted September 1, 2020

\begin{abstract}
In this paper, the occurrence characteristics of the equatorial plasma bubbles (EPBs) using OI $630.0 \mathrm{~nm}$ all sky imager (ASI) night airglow observations over Kolhapur $\left(16.8^{\circ} \mathrm{N}, 74.2^{\circ} \mathrm{E}, 10.6^{\circ} \mathrm{dip}\right.$. Lat.) during the solar cycle- 24 are presented. These results are discussed in terms of season, solar and magnetic activity during years 2011 to 2018. The ASI observations were only carried out during January to May and October to December months due to unfavorable weather conditions. The results suggest that while January, February and December are the only months where EPBs were found to occur over Kolhapur in any year, but the percentage of occurrence of EPBs during these months suggests their low occurrence rate during solar minimum. A total of 683 nights of observations were carried, out of which, 93 nights are found to be magnetically disturbed nights having Ap>18. In addition, the ASI observations are also correlated with Pre-Reversal Enhancement of the vertical drift of the evening sector at Tirunelveli on few storm events for comparison. The important findings of this study are: 1) increase in the occurrence of EPBs with respect to the solar activity; 2) suppression of EPBs on 71 disturbed nights, while enhancement of EPBs on 22 nights under magnetic disturbance; 3) EPBs occurrence during equinox months is found to be higher than winter months during ascending phase of solar cycle-24.; and, 4) EPBs are mostly observed in the pre-midnight sector in the high solar activity (HSA) period, while they are seen in the post-midnight to dawn sector during the low solar activity (LSA) period. We also noticed non-occurrence of EPBs during equinox month in the year 2018 which seems to be peculiar and needs further investigations.
\end{abstract}

Keywords: EPB; Night airglow; Magnetic storm; Ionospheric irregularity. 


\section{Onkar B. Gurav et al.}

\section{Introduction}

The equatorial spread-F (ESF) is a nighttime phenomenon occurring at low and equatorial ionosphere. The optical signatures of the ESF are often named as equatorial plasma bubble (EPB) or the equatorial plasma depletion (EPD). Severe disturbances may result from such EPBs in trans-ionospheric radio propagation at Giga Hertz frequency range affecting the communication and navigation systems. The first observation of this magnetically North-South aligned structures within the low-intensity regions of OI $630.0 \mathrm{~nm}$ airglow images during the period of spread-F observations were observed by Weber et al. [1978]. The all-sky images of OI 630.0, $557.7 \mathrm{~nm}$ and $777.4 \mathrm{~nm}$ emissions were well appreciated with these low intensity regions. These optical signatures of all sky imager shows low electron density patches which are termed as EPBs. Many researchers have studied the different characteristics of EPBs such as zonal drift velocity [e.g. Mukherjee and Shetti 2008, Nade et al., 2013 \& 2015, Taori et al., 2013, Sripathi et al., 2016, Gurav et al., 2018], occurrence [e.g. Sharma et al., 2014, Sharma et al., 2017a,b], generation mechanism and its morphological features [Sinha and Raizada 2000, Taori et al., 2011, Narayanan et al., 2014 and 2016, Gurav et al., 2019] over Indian sector. Dabas et al. [2007] have studied the occurrence features of equatorial spread-F irregularities and their latitudinal variation using concurrent instruments such as digital ionosondes located at Trivandrum $\left(8.21^{\circ} \mathrm{N}\right)$, Waltair $\left(17.71^{\circ} \mathrm{N}\right)$ and Delhi $\left(28.61^{\circ} \mathrm{N}\right)$ and $4 \mathrm{GHz}$ scintillation observations at Sikandarabad $\left(26.81^{\circ} \mathrm{N}\right)$ and Chenglepet $\left(10.41^{\circ} \mathrm{N}\right)$, and $250 \mathrm{MHz}$ scintillations observations at Bhopal (23.21N) during equinoxes period. Apart from summer months, they found maximum spread F occurrence at Trivandrum, minimum at Delhi and moderate at Waltair. They also suggested that the spread-F activity witnessed at Trivandrum, Waltair and Delhi occurred only when equatorial $\mathrm{E} \times \mathrm{B}\left(\mathrm{h}^{\prime} \mathrm{F}\right)$ is more than about $15 \mathrm{~m} / \mathrm{s}(325 \mathrm{~km}), 20 \mathrm{~m} / \mathrm{s}(350 \mathrm{~km})$ and $25 \mathrm{~m} / \mathrm{s}(375 \mathrm{~km})$ respectively. Ghodpage et al., [2014], have calculated the zonal drift velocity of EPBs observed from Kolhapur $\left(16.8^{\circ} \mathrm{N}, 74.2^{\circ} \mathrm{E}, 10.6^{\circ} \mathrm{N}\right.$ dip. lat.) and Gadanki $\left(13.51^{\circ} \mathrm{N}, 79.21^{\circ} \mathrm{E}, 6.51^{\circ} \mathrm{N}\right.$ dip lat.) during March 2012 . Their study revealed that the drift velocity calculated in Kolhapur varies from $124 \mathrm{~m} / \mathrm{s}$ to $181.8 \mathrm{~m} / \mathrm{s}$, whereas at Gadanki, it varied from $116.3 \mathrm{~m} / \mathrm{s}$ to $160.3 \mathrm{~m} / \mathrm{s}$. Sharma et al., [2017b] studied occurrence of scintillation recorded in VHF scintillation data for the period of 2011 to 2015 over Kolhapur. They found that, the percentage occurrence of strong scintillations decreases with increase in solar activity. However, the moderate scintillations are found to be increased with solar activity. Also, Kelley et al., [2002], reported the observations of EPBs which reached to altitude of $1500 \mathrm{~km}$ over the magnetic equator and mapped magnetically to latitudes well north of Maui, Hawaii $\left(20.71^{\circ} \mathrm{N}, 203.83^{\circ} \mathrm{E}\right)$. They found that the radio signals from all the Global Positioning System (GPS) satellites were severely disturbed in their field of view, whenever the corresponding line of sight of signals passed through one of the turbulent regions of the ionosphere. An interesting observations by Ray et al., [2003] from Calcutta ( $32^{\circ} \mathrm{N}$ dip lat.) with 1.5 GHz L-band signals reveal that the scintillation occur in patches of duration changing from a few minutes to about several hours (48 hr $55 \mathrm{~min}$ ). Also, Ray and Das Gupta [2007] reported statistical occurrence of scintillation patches for a long-term study (minimum to high sunspot number (1996-2000)) at $1.5 \mathrm{GHz}$ observed from Calcutta. They observed intense scintillations ( $>20 \mathrm{~dB}$ ) during solar maximum period of 1998-2000 and also scintillation activity is proportional to solar cycle. Further, during the equinoctial months of AugustOctober and February-April, occurrence of scintillations is less during magnetically active conditions than during quiet. It is noteworthy that a number of studies based on the radio methods (as quoted above) have reported statistics on the spread-F. The radio observations such as GPS/TEC depicts the F-region peak electron density behavior, the $630 \mathrm{~nm}$ airglow emissions are weighted more towards the base height of F-region. While the radio observations suggest ionospheric behavior, airglow measurements are outcome of thermosphereionosphere coupled system response. Therefore, establishing statistics using optical data is valuable.

In the above context, Sharma et al., [2017a], have reported the occurrence of EPBs for the period of 2011-2015 (increasing phase of solar cycle-24) from the Kolhapur and found that the occurrence is very much dependent on the solar activity. Here the ASI observations for the period of 2011-2018 are used which falls under the solar cycle-24 and covers the increasing as well as decreasing phases. The purpose of this paper is to examine the changes in the EPBs occurrence with respect to season, solar and magnetic activity during increasing as well as decreasing phases of solar cycle using optical airglow data. Though some preliminary results were presented by Sharma et al., [2017a], the results presented in this study are based on a superset of data, new and are substantially long period of optical observations, not reported till date. Also, the occurrences on disturbed nights are separately studied. The disturbed nights on which geomagnetic storms were commenced are classified 
following Aaron [1991]. We use Dst Index to categorize these storms. Further, day-to-day variabilities in EPB occurrence is still an intriguing issue for global equatorial aeronomy community as no model exist until today to predict the occurrence of EPBs. It remains a mystery that on which particular night EPB can occur and whether on next consecutive night it will occur or not. As far as Indian sector is concerned, to the best of our knowledge no attempt has been made earlier to study the EPB occurrence using the all sky imager data for such a large period (08 years). Although various researchers have studied different features of EPBs and associated dynamics using ASI data recorded from different locations of India. Some of them includes seeding of EPBs by gravity waves [e.g. Sivakandan et al 2019], MSTIDs [e.g. Taori et al., 2015, Narayanan et al., 2019], geomagnetic disturbances [Sripathi et al., 2018] etc. Many of the research regarding EPBs were done on its case wise classification in the context of their morphology and associated dynamics. However, there exists no study related to their occurrence percentage with respect to day, month, year, solar and magnetic activity based on solar cycle data over Indian region. The present study fills this gap and provides statistics of the EPBs occurrence during both increasing and decreasing phases of the solar cycle- 24 .

\section{Data and Methodology}

A monochromatic All-Sky Imager was designed and built by KEO Scientific Ltd. Canada for the Indian Institute of Geomagnetism, New Panvel, India. The design of a charged coupled device (CCD) based imaging system has been discussed by Mendillo et al., [1997]. The various emission lines originating at different ionospheric/thermospheric and mesospheric heights can be studied almost simultaneously. However in the present study, OI $630.0 \mathrm{~nm}$ emission is used which comes from an altitude of $\sim 250 \mathrm{~km}$. The night airglow observations are carried out for 7 nights just before and after the new moon night. The high-resolution (1024 $\times 1024$ pixels $=1 \mathrm{MP}), \mathrm{CCD}$ based ASI, has field of view of $180^{\circ}$ but for observation the FOV is restricted to $140^{\circ}$ FOV ( $\pm 70^{\circ}$ zenith angle) to avoid city light noise and therefore obtain better imaging (Figure 1 for FOV). The east-west distance of approximately $1220 \mathrm{~km}$ in diameter at an altitude of $250 \mathrm{~km}$ is covered by this field of view. The CCD detector is back-illuminated with an array of $1024 \times 1024$ pixels having 16 bits of resolution. The $\mathrm{CCD}$ is thermo-electrically cooled $\left(-80^{\circ} \mathrm{C}\right)$ to reduce dark counts before the operation. Further explanation of ASI can be found in Ghodpage et al., [2014]. The raw images inferred from ASI are processed using the averaging method which includes several steps. More details about the ASI technique as well as the image processing method can be found in Sharma et al., [2017a, 2018]. In addition to optical observations, we also used h'F (km) and foF2 (MHz) over Tirunelveli $\left(8.73^{\circ} \mathrm{N}, 77.70^{\circ} \mathrm{E}, 0.5^{\circ} \mathrm{N}\right.$ dip. lat.) on few occasions to investigate the relationship between the EPBs and evening time pre-reversal enhancement (PRE).

The ASI observations start from evening time at around 19:30 LT (LT $=$ UT + 05:30 hh:mm) and ends at next day dawn time around 05:30 LT. For OI 630.0 nm emission monitoring, the time difference between two images is kept almost constant (i.e., 6 minutes interval). Accordingly, from 19:30 LT to 05:30 LT, approximately 100 images are recorded on each night of observations. The hourly occurrence is calculated by observing the presence of EPBs in every one hour data for the whole night observations. Since in one hour ASI data there are 10 images, if out of this 5 images show EPB presence then the hourly occurrence during that hour is $50 \%$. The number of EPBs (i.e. group of EPBs) per night have not been taken into account, rather we have analyzed only the presence or absence of EPBs (i.e. occurrence) in ASI image. For example, in some night, 10 EPBs are noted in ASI image and their duration is 10 hours but in some cases 10 EPBs are noted but their duration is 7 to 8 hours. So the occurrence may vary depending upon the persistence of EPBs in ASI image. If there is a single EPB noted in all 10 images (i.e. 1 hour) then the occurrence is $100 \%$. Further, if there are 5 EPBs noted in all 10 images (i.e. 1 hour) then also we counted the occurrence as $100 \%$. In this way, the hourly percentage occurrence is calculated. Kolhapur location is situated at northern crest of Equatorial Ionization Anomaly (EIA) and its dip latitude is $10.6^{\circ} \mathrm{N}$. The declination of this location is $\sim 0.54 \mathrm{~W}$. It is a low latitude station and hence persist maximum occurrence of EPBs. When EPBs are generated at dip equator, they develops vertically and simultaneously gets mapped to either side of the equator and Kolhapur is located close to northern side of equator where EPBs are easily detectable. 


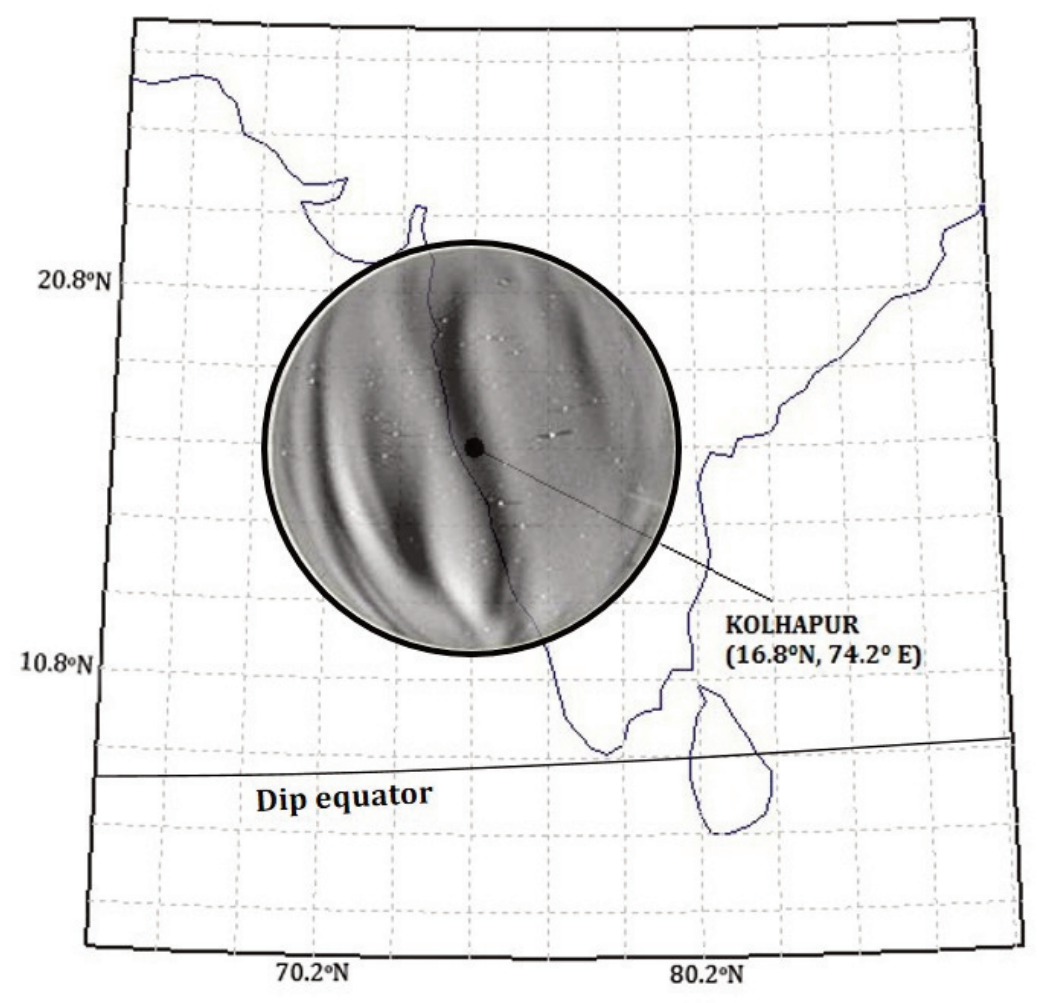

Figure 1. The field of view (FOV) of all sky imager which covers the night sky with a zenith angle range of about $70^{\circ}\left(140^{\circ}\right.$ FOV) over Kolhapur. This corresponds to horizontal distance about nearly $1220 \mathrm{~km}$ in diameter at an altitude of $250 \mathrm{~km}$. The ASI sample image of OI $630.0 \mathrm{~nm}$ is obtained with $140^{\circ}$ FOV as shown in black circle. The dark bands in the images are the signatures of EPBs.

\section{Results and Discussion}

\subsection{EPBs hourly occurrence}

The EPBs occurrence during geomagnetically quiet days for the period of 2011-2018 is calculated as per the procedure described in Data and Methodology section. This variation is depicted in Figure 2. In this figure, the blue background stands for zero occurrence of EPBs. Also, in present study, very dense cloud coverage images/nights are not taken into account. Figure 2 depicts the hourly variation of the percentage occurrence of EPBs during quiet nights only (590 days of observation). The disturbed nights are sorted and studied separately. Table 1 depict the summary of observation data that is used to study the quiet nights. In Figure 2, it is observed that the onset of EPBs occurs around 19:30 LT and increases up to pre-midnight period and then decreases towards dawn. However on some of the nights, occurrence times have onset shifted beyond 19:30 LT while some nights have seen the occurrence of EPB onset only after mid-night period. There are more number of EPBs onsetting beyond midnight during low solar activity period (e.g. 2018) compared to high solar activity (e.g. 2013 - 2014). Here, the occurrence is maximum during initial years 2011-2012 and it is minimum in the years 2013-2014. As described in Sharma et al., [2017a], the ASI data of OI $630.0 \mathrm{~nm}$ images from October 2013 to March 2014 are not available because of some technical issues. So the low percentage occurrence in 2013-2014 could be due to the lesser number of observation nights as compared to other years. In year 2015, the occurrence seems to be again maximum as this is a near solar maximum year. Further in 2016, the occurrence is maximum prior to pre-midnight hours. And finally, the occurrence percentage decreases towards the 2018 which is near solar minimum year. From this analysis, it is confirmed that, the solar activity is positively correlated with the EPBs occurrence. It is interesting to note that, during the increasing and decreasing phases, the percentage occurrence seems to be higher and lower respectively. This concludes that the EPBs occurrence is also dependent on the phase of solar cycle. 


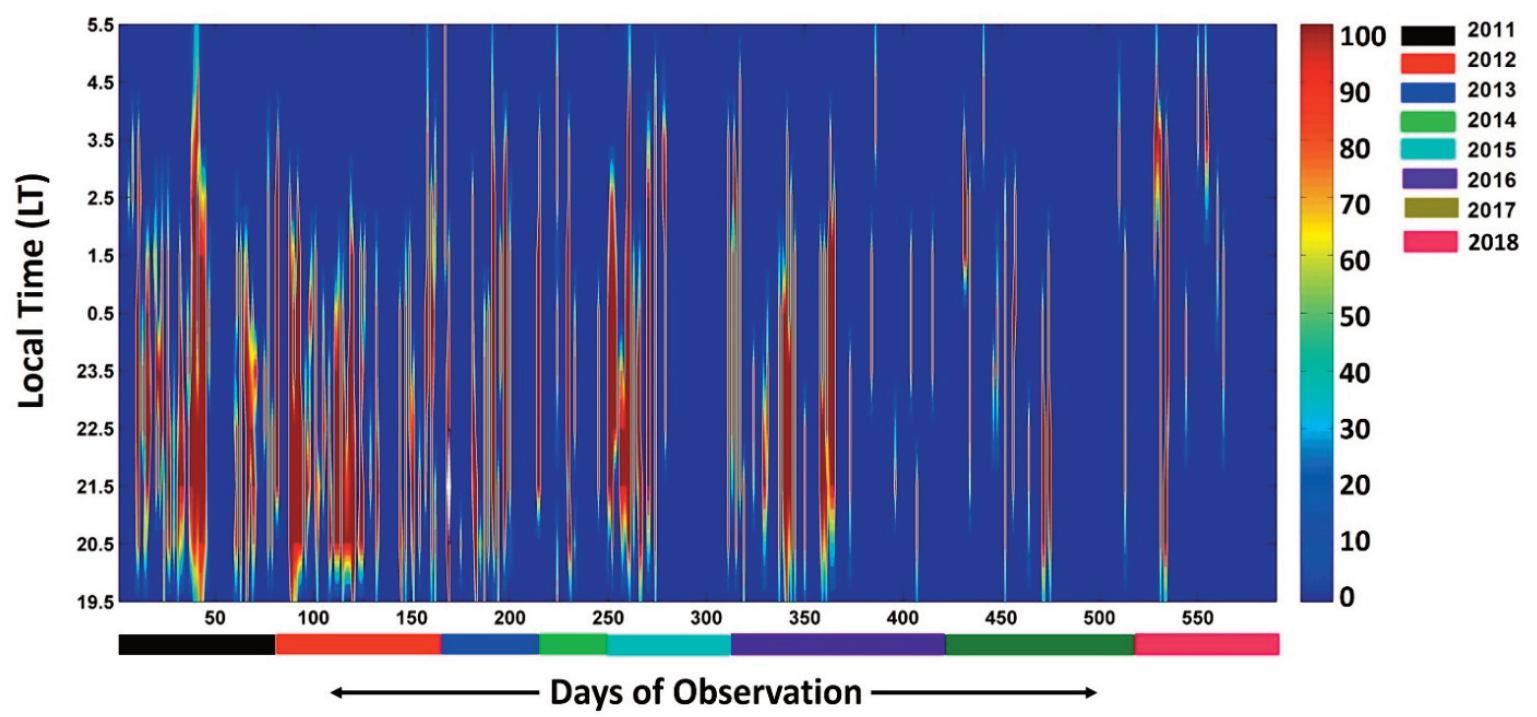

Figure 2. The hourly \% occurrence of EPBs for the days of observations from year 2011-2018. Blue portion indicates zero occurrences of EPBs.

\begin{tabular}{ccccccc} 
Year & $\begin{array}{c}\text { Quite } \\
\text { nights }\end{array}$ & $\begin{array}{c}\text { Disturbed } \\
\text { nights }\end{array}$ & $\begin{array}{c}\text { Total number of } \\
\text { observation } \\
\text { nights }\end{array}$ & $\begin{array}{c}\text { Total number of } \\
\text { images recorded (a) }\end{array}$ & $\begin{array}{c}\text { Event } \\
\text { images (b) }\end{array}$ & $\begin{array}{c}\text { Yearly \% } \\
\text { Occurrence } \\
\text { (b/a* 100) }\end{array}$ \\
\hline 2011 & 86 & 9 & 95 & 9399 & 2165 & 23.0343 \\
\hline 2012 & 76 & 8 & 84 & 8750 & 2007 & 22.9371 \\
\hline 2013 & 48 & 1 & 49 & 4106 & 812 & 19.7759 \\
\hline 2014 & 34 & 3 & 37 & 3335 & 524 & 15.7121 \\
\hline 2015 & 72 & 17 & 89 & 7627 & 1412 & 18.5131 \\
\hline 2016 & 118 & 26 & 144 & 11322 & 1160 & 10.2455 \\
\hline 2017 & 105 & 29 & 134 & 11968 & 941 & 7.8626 \\
\hline 2018 & 51 & 0 & 51 & 6383 & 139 & 2.1776 \\
\hline Total & $\mathbf{5 9 0}$ & $\mathbf{9 3}$ & $\mathbf{6 8 3}$ & $\mathbf{6 2 8 9 0}$ & $\mathbf{9 1 6 0}$ & \\
\hline
\end{tabular}

Table 1. Summary of eight year (2011-2018) observation night's data.

\subsection{Monthly averaged percentage occurrence of EPBs}

The EPBs percentage occurrence on day-to-day basis is calculated by measuring the ratio of number of images in which EPBs are present to the total number of images logged during that night multiplied by 100 . The ASI is usually operated in the months of January, February, March, April, May, October, November and December. The ASI is not operated in the months of June to September due to unfavorable sky conditions. Figure 3, depicts the monthly percentage occurrence of EPBs (bottom panel) and corresponding $10.7 \mathrm{~cm}$ solar-flux (top panel) during the years 


\section{Onkar B. Gurav et al.}

2011-2018. The monthly percentage occurrence of EPBs is calculated by clubbing daily averaged occurrence of all the observable nights in a particular month. Further, this daily averaged occurrence of all the days is added and divided by total number of nights in that month which we call the relative occurrence. From Figure 3, it is observed that the monthly percentage occurrence is positively correlated (Correlation Coefficient: 0.45 ) with corresponding solar flux. Mendillo et al., [1992], stated the conditions for growth of EPBs which are: (1) the alignment of the terminator with geomagnetic flux tubes as suggested by Tsunoda [1985]; (2) the lack of a strong trans-equatorial thermospheric wind that might decrease the growth rate as proposed by Maruyama and Matuura [1984]; (3) the quick rise of the F-layer just after sunset and (4) the presence of a seed perturbation. Also, it is well believed that the solar activity has direct impact on the generation of EPBs. Xiong et al. [2010] have investigated the characteristics of EPBs using multi-year data base i.e., 2001-2009 of CHAMP Planar Langmuir Probe (PLP) and GRACE K-Band Ranging (KBR1B) observations measured at the altitudes of CHAMP (300-400 km) and GRACE ( 500 km) respectively. They found that the occurrence seems to be linearly increasing with that of solar-flux at about the similar rate at CHAMP and GRACE. Further, they observed that the EPBs associated with higher/lower apex altitude exhibits strong/weak occurrence rates. In the present study, we observed lesser percentage occurrence of EPBs during the decreasing phase of solar-cycle 24 as can be seen in Figure 3.

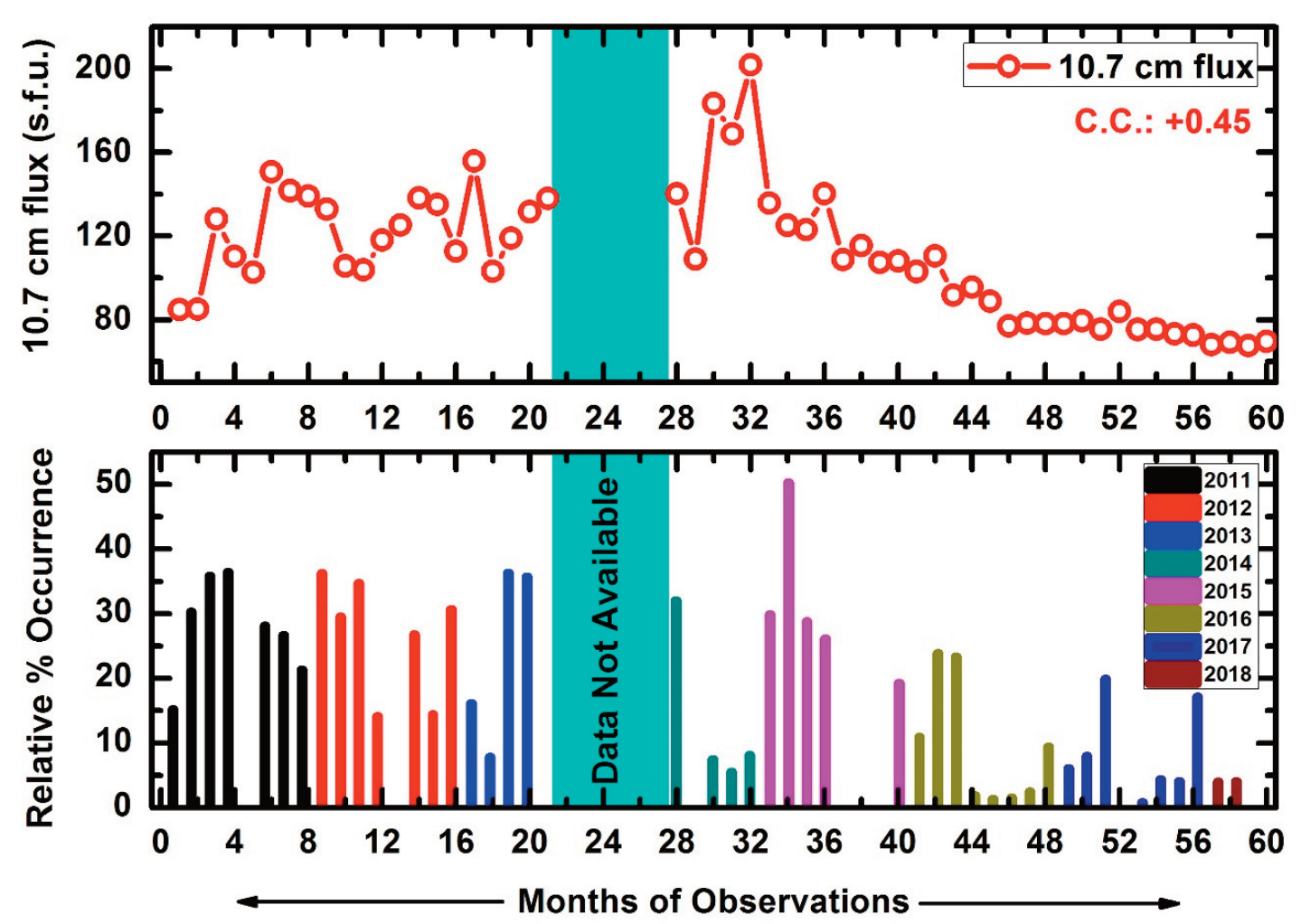

Figure 3. The monthly averaged \% occurrence of EPBs for the period of 2011-2018 along with corresponding $10.7 \mathrm{~cm}$ solar flux.

Many researchers have investigated the occurrence statistics of EPBs and its generation/inhibition for several decades. Deng et al., [2013], reported the L-band scintillations observed in GPS data available from July 2008 to March 2012 at the northern crest of equatorial anomaly stations in Guangzhou and Shenzhen of South China. They found that in equinox, scintillation is observed only prior to midnight hours during quiet solar-activity years. Also more scintillation were observed in the pre-midnight hours of both the equinox and the winter months during high solar-activity years. Also, GPS scintillations were noted in the after-midnight hours of summer and winter months. They found that, the period of scintillation patches were mostly less than 60 min and it is extended to about $180 \mathrm{~min}$ in low and high solar activity years respectively. Magdaleno et al., [2017], using GPS 
derived slant total electron content (STEC) reported the climatological picture of EPBs for the period 1998-2008. Their analysis shows that majority of the EPBs occur at the magnetic equator and in the South America-Africa sector, whereas their occurrence shrinks as the distance from the magnetic equator increases. Further they observed, the period of the TEC depletions and its depth also increases at the equator but they get decreases away from the equator. They also observed maximum number of EPBs during high solar activity. Smith and Heelis [2017], found that post-midnight plasma bubbles appear preferentially at solar minimum with no seasonlongitude dependence. Sun et al., [2016], by making use of ASI setups over Chinese longitude sector presented the statistical analysis of EPBs. They observed the EPBs percentage occurrence was 8.3\% in 2013 and $17.2 \%$ in 2014. The statistical analysis presented in the current study has findings which are in agreement with the previously reported literature. The important thing to note is that the occurrence varies in both the increasing and decreasing phase of solar-cycle 24 over Kolhapur.

\subsection{The month wise variation in EPBs occurrence}

The month wise relative occurrence is plotted for all the months during 2011-2018 along with monthly averaged $10.7 \mathrm{~cm}$ flux as shown in Figure 4. The 2011-2015 duration is considered as increasing phase of solar cycle while 2015-2018 is considered as decreasing phase of solar cycle in the present study. This occurrence is calculated in the same way as described in earlier section. The January and February are the only months which exhibits the EPBs occurrence throughout the period under consideration. Other months do not show occurrence in the year 2018. In the year 2013 (which is a near solar maximum year), the month of January and February shows interestingly low EPB occurrence similar to solar minimum phase. Further in March month, the occurrence seems to be almost unchanged in the ascending phase but it seems to be decreasing in descending phase of the solar cycle. Further in the last year 2018 the occurrence in March is zero. In the month of April, the occurrence is somewhat fluctuating in the increasing phase of the solar and it is decreasing towards solar minimum. It seems minimum in 2016 and further it is zero in later years. In the month of May there were no EPBs during increasing phase of solar cycle but very small occurrence is noted in decreasing phase (in the years 2016 and 2017). In future study, we will be investigating the reasons behind the summer month occurrence (i.e. May month). Further, in October and November months, the occurrence is maximum in increasing phase of solar cycle and it is minimum at solar maximum year 2014 and further follows decreasing trend towards descending phase. Here, in year 2015, the EPBs occurrence is found to be zero in these two months which needs further investigations. Finally, in the month of December, EPBs occurrence is always present (except 2018) similar to January, February and March irrespective of phases of solar cycle. From this analysis, we suggest that the January, February, March and December are the months to expect EPBs occurrence throughout the solar cycle. Also, no EPBs were observed during equinox months except January-February for solar minimum year (Please refer section 3.4 for further information regarding non-occurrence in equinox months).

Sun et al., [2016], from their study, states that, $10 \%$ of total occurrence arises in November months but nil occurrence in December months of 2012, 2013 and 2014. However, in the present investigation, we observed that the occurrence of EPBs is nil in the month of May in increasing phase of solar-cycle but the occurrence is decreasing towards solar maximum in the November months. This discrepancy might be due to the differences in the longitude of these locations. Also, Makela et al. [2004] have analyzed the seasonal occurrence of EPBs using airglow and GPS scintillation measurements. These were collected between January 2002 and August 2003 from the Haleakala Volcano, Hawaii $\left(20.71^{\circ} \mathrm{N}, 203.83^{\circ} \mathrm{E}\right)$. They reported that the probability for EPB growth is observed as maximum in the data of April (45\%) and September (83\%). Further, a wide maxima of occurrence is observed during June to October (62\%). However in present study maximum occurrence is seen in the months of January, February and December from low to high solar activity. Recently, Sharma et al., [2017b] performed statistical analysis of scintillation activity using spaced VHF scintillation monitoring unit over Kolhapur, low latitude Indian region. They also found the maximum scintillation in the equinox months (March-April), moderate in winter months (January-February) and lower in summer months (May-September). The similar results were also observed in the past by various researchers over Indian zone (e.g. Vyas and Dayanandan [2011], Chatterjee and Chakraborty [2013]). So with this, it should be noted that the statistics regarding occurrence shown in this study is in agreement with the previously reported studies over India region. 


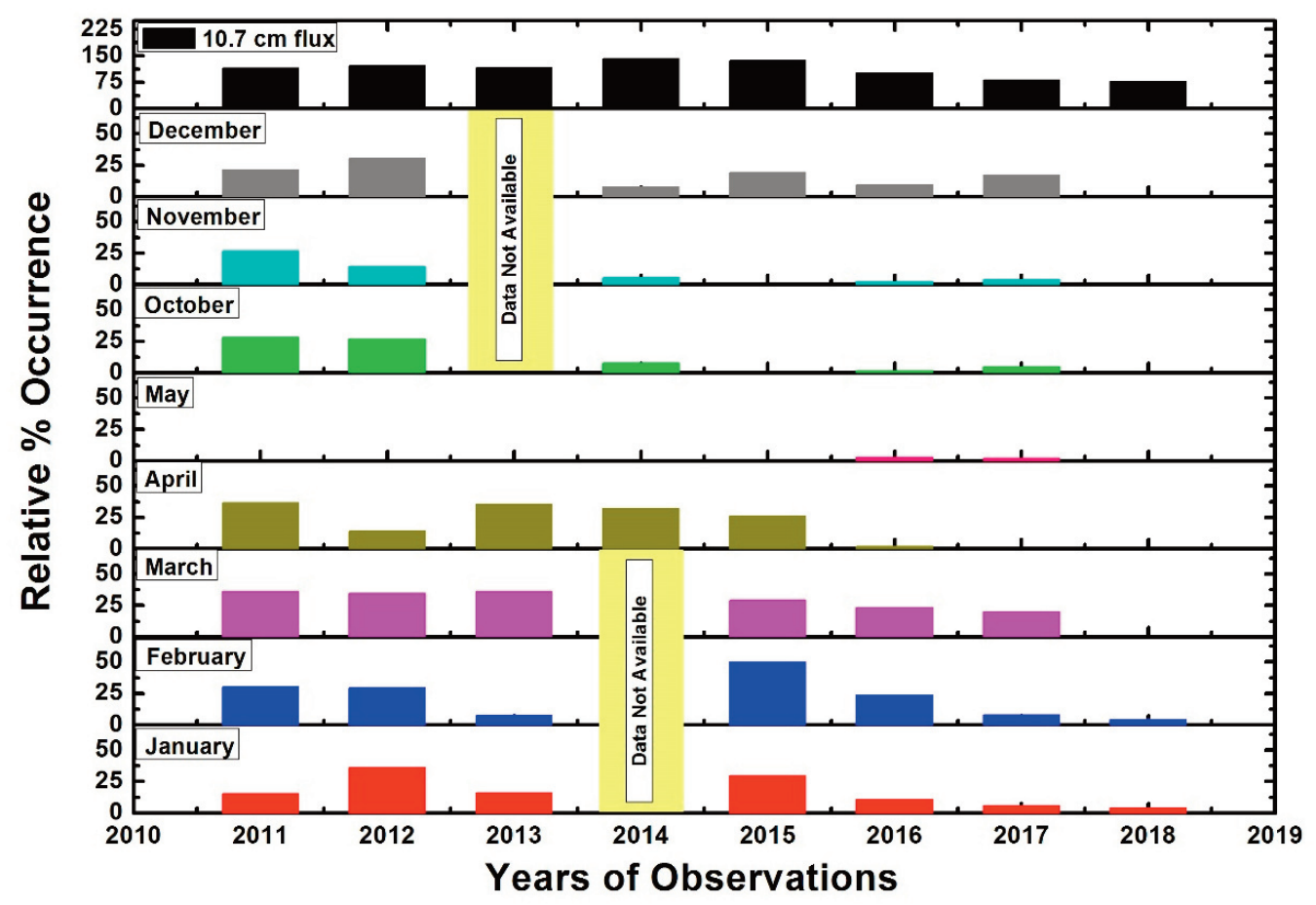

Figure 4. Month wise variation in percentage occurrence of EPBs for the year 2011-2018 along with monthly averaged $10.7 \mathrm{~cm}$ flux. The yellow colored portion indicates data not available.

\subsection{Hourly seasonal occurrence of EPBs}

For seasonal analysis, the months are categorized as Equinox (March-April-September-October), Summer (MayJune-July-August) and Winter (January-February-November-December) [Vyas and Dayanandan 2011]. The occurrence is calculated on hourly basis for each month to get the seasonal variation as shown in Figure 5 (a). The black vertical bars depicts the occurrence for equinox months and the red vertical bars depicts the occurrence for winter months. In the year 2014, the data for the months of January to April is not available. It is observed that the equinox months exhibits greater occurrence as compared to winter months for increasing phase of solar-cycle. However, the occurrence for equinox and winter months in descending phase is do not show any significant pattern. Also, we observed the zero occurrence in equinox months for the solar minimum year 2018. It is obvious that during equinox EPBs are more frequently observed, but here in the month of March 2018 no EPBs were seen. This is mainly because of low solar activity period.

We have analyzed the plots of equinox and winter months for increasing as well as decreasing phase by calculating the Gaussian parameters. Figure 5 (b) indicates the Gaussian fit for equinox and winter for the year 2011. These are only sample plots. The same fitting has been carried out for all the years which is not shown here but the parameters obtained by this analysis are shown in Table 2. The Gaussian fit gives the information about the time span and the peak time of occurrence EPBs throughout the night. From Table 2, it is seen that, the peak time for equinox months is decreasing between 2011 and 2013. Meaning, the peak occurs earlier in the evening in 2013 compared to 2011. But suddenly the peak is found at $24 \mathrm{LT}$ for the year 2014 and then it has decreased towards solar minimum year. While for winter months no trend is observed in the peak maximum of EPBs. Also, the width of the fit provides a mean estimate on the persistence of the EPBs. For example, for winter months in 2011, the width is about 5 hours which agrees well with the data shown in Figure 2. We note that maximum duration hours of occurrences is 8.4 hours during winter months of the year 2016 followed by 8.3 hours which was in year 2014 equinox months, followed by 8.1 hours in 2017 in winter months. In general, it was expected that EPBs are conspicuous during equinox months; however, in the equinox months of two years out of eight (2017 and 2018) does not agree with this presumption and needs to be scrutinized further. 
Occurrence climatology of EPBs during solar cycle-24 in low latitude station, Kolhapur
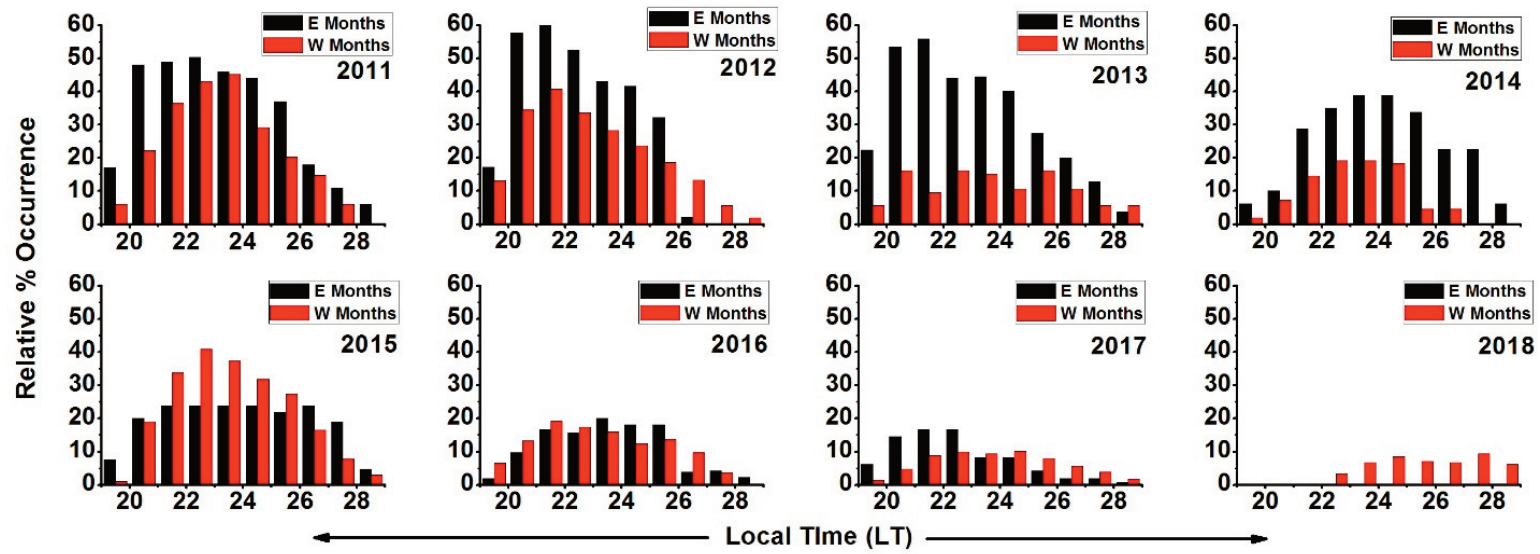

Figure 5 (a). The hourly \% occurrence of EPBs for Equinox (March, April and October) and Winter (January, February, November and December) seasons for the period of 2011-2018.

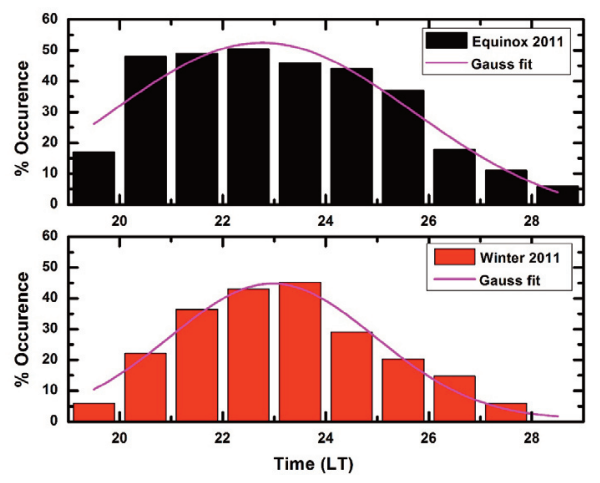

Figure 5 (b). The hourly \% occurrence of EPBs for Equinox (black) and winter (red) months of 2011. The pink curve represents the Gaussian fit.

\begin{tabular}{cccccc} 
S. N. & $\begin{array}{c}\text { Observation } \\
\text { year }\end{array}$ & Season & $\begin{array}{c}\text { Maximum occurrence } \\
\text { of EPB (\%) }\end{array}$ & $\begin{array}{c}\text { Time duration of EPB } \\
\text { occurrence (hrs.) }\end{array}$ & $\begin{array}{c}\text { Peak max. } \\
\text { Occurrence of } \\
\text { EPB (hrs.) }\end{array}$ \\
\hline 1 & 2011 & E & 56.81 & $6.9 \pm 2.9$ & 22.76 \\
\hline 2 & & W & 44.03 & $4.7 \pm 1.9$ & 22.96 \\
\hline 3 & 2012 & E & 65.41 & $5.9 \pm 2.5$ & 22.54 \\
\hline 4 & & W & 34.37 & $5.6 \pm 2.4$ & 22.21 \\
\hline 5 & 2013 & E & 51.11 & $6.7 \pm 2.8$ & 22.26 \\
\hline 6 & & W & 52.49 & $5.4 \pm 1.7$ & 23.43 \\
\hline 7 & 2014 & E & 60.12 & $8.3 \pm 3.5$ & 24.09 \\
\hline 8 & & W & 21.36 & $4.2 \pm 1.7$ & 23.07 \\
\hline 9 & 2015 & E & No fit & & \\
\hline 10 & & W & 45.08 & $5.8 \pm 2.4$ & 23.36 \\
\hline 11 & 2016 & E & 22.34 & $5.7 \pm 2.4$ & 23.78 \\
\hline 12 & & W & 32.89 & $8.4 \pm 4.4$ & 21.79 \\
\hline 13 & 2017 & E & 15.40 & $3.9 \pm 1.6$ & 23.71 \\
\hline 14 & & W & 14.78 & $8.1 \pm 3.4$ & \\
\hline 15 & 2018 & E & Zero occurrence & & \\
\hline 16 & & 10.72 & $6.9 \pm 3.3$ &
\end{tabular}

Table 2. Parameters observed form Gaussian fit. 


\section{Onkar B. Gurav et al.}

\subsubsection{Non-occurrence of EPBs during equinox of solar minimum year 2018}

In our observation days from the all-sky imager, the EPBs presence is not observed during March-April 2018 which is solar minimum year. As Kolhapur lies at $10.6^{\circ} \mathrm{N}$ dip latitude, it is necessary that the EPBs would have had to reach an apex height of $\sim 300$ to $400 \mathrm{~km}$ at the equator, then only EPBs can be visible at Kolhapur location after sunset. Due to quiet solar activity, there might be a lack of sufficient pre-reversal in the post sunset electric field which ultimately reduces the apex height and hence there is no occurrence of EPBs at latitudes too far off the equator. To investigate the non-occurrence seen at Kolhapur, we have analyzed GPS TEC data from Hyderabad station $\left(17.02^{\circ} \mathrm{N}\right)$ which is located at nearly same latitude as of Kolhapur. Figure 5 (c) depicts a sample plots of VTEC with elevation angles for a solar maximum and minimum day. Usually, if there is EPB occurrence in GPS data, we can see the depletion in VTEC in the nighttime which are the manifestations of EPBs. Here, for the solar minimum day (i.e. 04-05 April 2018, top panel), we see that there are no any depletions observed in VTEC which indicates that no EPBs were present. On the other hand, if we see VTEC for solar maximum day (i.e. 25-26 April 2015, bottom panel), then the depletions in VTEC are clearly seen as indicated by red arrows. In this way, we have checked VTEC depletions if any for the months of March-April 2018 and obtained results are shown in Table 3. It is noted that, no such depletions in GPS TEC data are observed in all the observation nights of March-April 2018. This indicates that, the EPBs are not present in the equinox of solar minimum. Further, it should be mentioned that, the TEC depletion beyond 5 TEC unit are considered as EPBs presence. In all the observation nights no such depletions were seen.
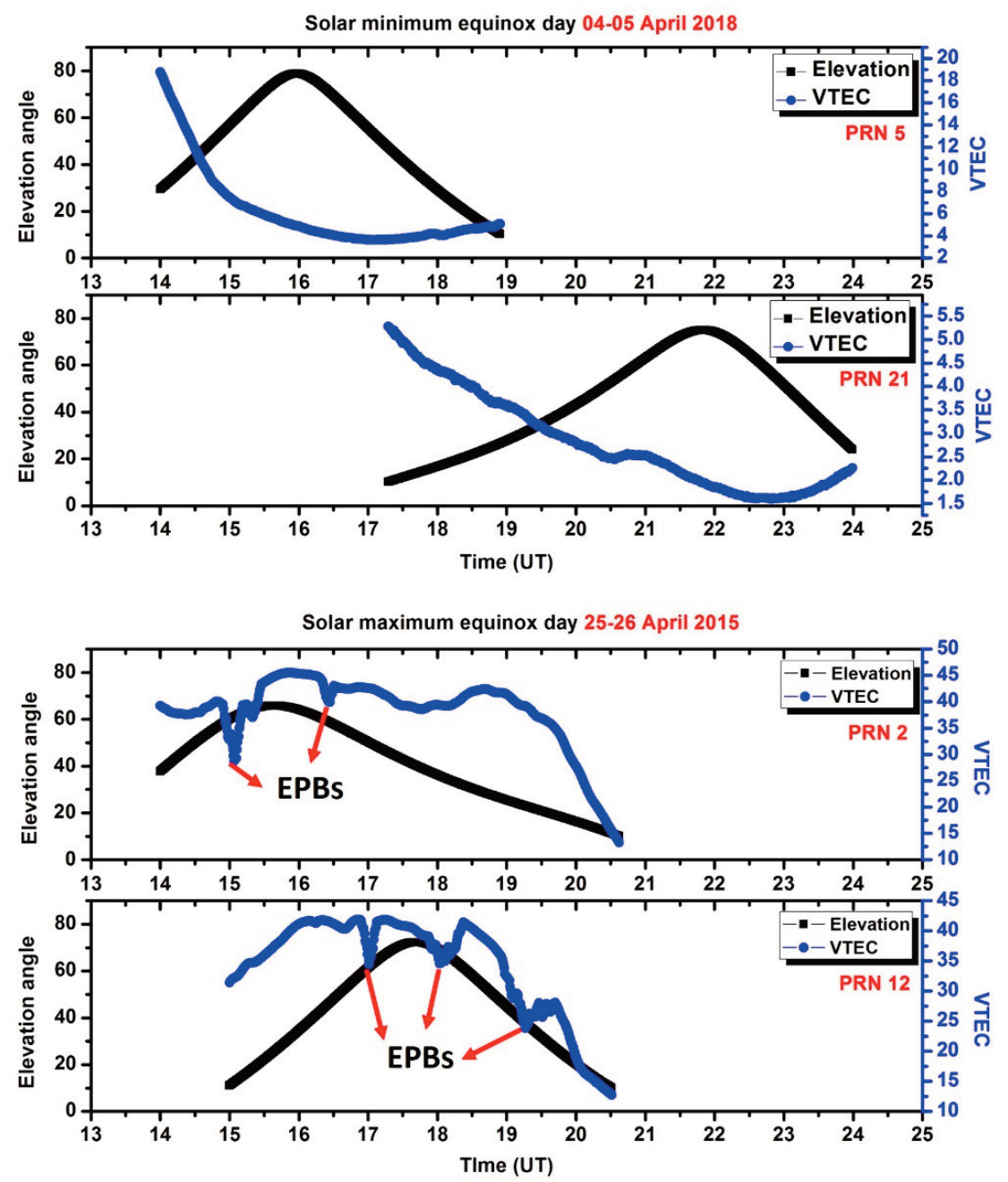

Figure 5 (c). The variation of VTEC with elevation angle over Hyderabad station during solar minimum and maximum days. The depletion in VTEC are the signatures of EPBs on 25-26 April 2015. 


\begin{tabular}{ccccccc} 
Sr. No. & Date of Observation & \% Occurrence & Ap (nT) & $\begin{array}{c}\text { Maximum Dst } \\
\text { Excursion time (LT) }\end{array}$ & $\begin{array}{c}\text { Category } \\
\text { (Y/N) }\end{array}$ & $\begin{array}{c}\text { Duration in } \\
\text { which max. } \\
\text { excursion should } \\
\text { occur }\end{array}$ \\
\hline 1 & 16-17 November 2014 & 29.41 & 22 & 12.5 & I (Y) & 10 to 16 LT \\
\hline 2 & 22-23 December 2014 & 31.57 & 22 & 11.5 & I (Y) & \\
\hline 3 & 11-12 December 2015 & 22.22 & 20 & 12.5 & I (Y) & \\
\hline 4 & 01-02 February 2017 & 65.51 & 29 & 14.5 & I (N) & \\
\hline 5 & 10-11 March 2011 & 11.11 & 20 & 2.5 & II (N) & 00 to 06 LT \\
\hline 6 & 02-03 April 2011 & 9.09 & 20 & 1.5 & II (N) & \\
\hline 7 & 11-12 March 2016 & 14.73 & 23 & 2.5 & II (N) & \\
\hline 8 & 02-03 February 2017 & 37.07 & 21 & 0.5 & II (N) & \\
\hline 9 & 04-05 February 2011 & 7.33 & 21 & 2.5 & II (N) & \\
\hline 10 & 06-07 April 2011 & 40.19 & 26 & 0.5 & II (N) & \\
\hline 11 & 24-25 October 2011 & 37.38 & 31 & 6.0 & II (N) & \\
\hline 12 & 22-23 January 2012 & 19.04 & 21 & 2.5 & II (N) & \\
\hline 13 & 15-16 February 2012 & 55.2 & 21 & 0.5 & II (Y) & \\
\hline 14 & 15-16 March 2012 & 27.27 & 30 & 0.5 & II (N) & \\
\hline 15 & 14-15 December 2015 & 93.02 & 27 & 1.5 & II (Y) & \\
\hline 16 & 01-02 January 2016 & 18.75 & 22 & 5.5 & II (N) & \\
\hline 17 & 16-17 February 2016 & 40.98 & 38 & 0.5 & II (N) & \\
\hline 18 & 18-19 February 2016 & 33.33 & 29 & 5.5 & II (N) & \\
\hline 19 & 31 Jan-01 Feb 2017 & 23.46 & 24 & 1.5 & II (N) & \\
\hline 20 & 22-23 March 2017 & 58.58 & 27 & 5.5 & II (Y) & \\
\hline 21 & 23-24 March 2015 & 62.92 & 21 & 2.5 & II (Y) & \\
\hline 22 & 27-28 March 2017 & 32.96 & 54 & 19.5 & III (Y) & \\
\hline & & & & & & \\
\hline
\end{tabular}

Table 3. The classification of disturbed nights as per Aron's criteria. The Y/N indicates whether that night satisfy the Aron's criteria or not.

Many researchers around the globe investigated the seasonal variation in EPBs occurrence during high as well as low solar activity period. DasGupta et al. [1981] investigated the occurrence of F-region irregularities over the Indian sector using VHF-amplitude scintillation observations made at Calcutta $\left(27^{\circ} \mathrm{N}\right.$ dip. lat.) during the period April 1977 to February 1980. They observed that the scintillations increases unusually during the equinoxes and to a lesser extent during the December solstice, while in the local summer the occurrence shows little change. Singh et al. [2004] analyzed the VHF amplitude scintillation measurements carried out during the period of January 1991 to December 1993 in the decreasing phase of solar-cycle and April 1998 to December 1999 in the increasing phase of the next solar-cycle at Varanasi $\left(25.3^{\circ} \mathrm{N}, 83.0^{\circ} \mathrm{E}, 37^{\circ} \mathrm{N}\right.$ dip. Lat.), India. They reported that, increase in solar activity increases scintillations during winter (November-February) and near equinoxes (March-April; September-October), whereas it decreases the scintillations during summer (May-July). Chandra et al. [2003] investigated the spread F phenomenon logged by the ionosonde at Ahmedabad $\left(23.0^{\circ} \mathrm{N}, 72.4^{\circ} \mathrm{E} ; 14.0^{\circ} \mathrm{N}\right.$ dip. Lat.) and found that the occurrences of both the VHF-scintillation and the range spread F (RSF) are maximum, moderate and minimum at equinoxes, winter and summer respectively during high solar activity years. The present analysis is in agreement with the previously reported literature over Indian sector. As we also observed higher occurrence percentage during the equinox period when the solar activity is in increasing phase. 


\section{Onkar B. Gurav et al.}

From the regions other than India, Sahai et al. [1998] used a wide-angle imaging setup to record the OI $630.0 \mathrm{~nm}$ night-glow emission at Cachoeira Paulista $\left(22.7^{\circ} \mathrm{S}, 45.0^{\circ} \mathrm{W}, 15.8^{\circ} \mathrm{S}\right.$ dip. Lat.), Brazil. They observed minimum EPBs occurrence for the months of May to August, however during this period on some occasions at times of magnetic disturbances the presence of EPBs was prominent. In present study, for May months in increasing phase of solar cycle, the EPBs occurrence is zero, however during the decreasing phase on several nights the EPBs occurrence is noted as can be observed in Figure 4. Wiens et al. [2006] studied the EPBs occurrence with the help of an optical allsky imager installed in Asmara, Eritrea $\left(15.4^{\circ} \mathrm{N}, 38.9^{\circ} \mathrm{E}, 7^{\circ} \mathrm{N}\right.$ dip. lat.). They suggest that the probability of maximum occurrence of EPBs as well as GPS scintillations is around the equinoxes and it is minimum around the winter solstice. In addition to this, they suggests that, the maxima in equinox differs from the seasonal dependence at other longitude sectors, endorsing the longitude dependence of seasonal EPB occurrence behavior. Abdu et al. [1992] also suggest that, the global occurrence of EPBs shows a strong seasonal variability that depends on longitude. Buhari et al. [2017] investigated the occurrence rate of the equatorial plasma bubble with season, solar activity, and geomagnetic conditions using long-term data sets of Malaysia Real-Time Kinematics Network (MyRTKnet) from 2008 to 2013. Their results show that the EPB tends to occur successively over Malaysia in equinox season during high solar activity years. However, the occurrence day of EPBs was found to be relatively active only in equinoctial months during low solar activity. They suggest that the strong perturbation is essential for the development of the EPBs during low solar activity years. But in present study, we found lesser EPBs occurrence during equinoctial period for low solar activity.

\subsection{Occurrence on disturbed nights (Ap>18)}

\subsubsection{Daily Averaged}

The magnetically disturbed nights with $A p>18$ during the period 2011-2018 are sorted and their daily averaged percentage occurrence are plotted in the bottom panel of Figure 6 (a). Also, Ap indices (middle panel) which is the measure of magnetic disturbance and $10.7 \mathrm{~cm}$ solar-flux (top panel) which is the measure of solar activity on all corresponding disturbed nights are plotted in the same figure (i.e. Figure 6 (a)).

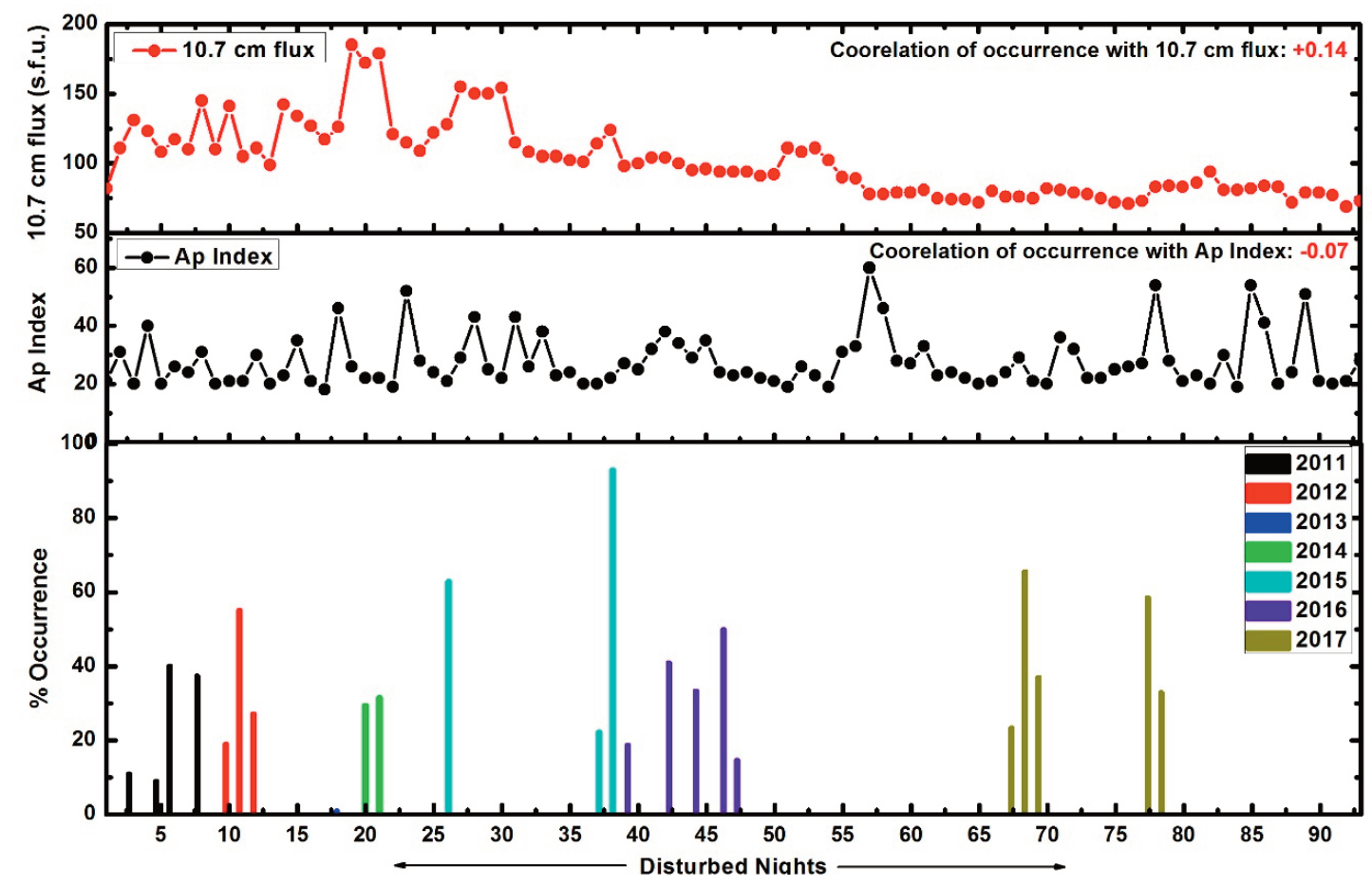

Figure 6 (a). The daily averaged \% occurrence of EPBs on disturbed nights (Ap >18) amongst seven years (2011-2017) and its relation with solar activity $(10.7 \mathrm{~cm}$ flux). 
It is found that, a large number of disturbed nights (i.e. 71 nights) amongst the period of 2011-2018 exhibits suppression of EPBs and remaining nights (i.e. 22 nights) have EPBs presence. Here, it is worthy to mention that, before occurrence of magnetic disturbance EPBs were present and when storm occurs on a particular night, the EPBs are not observed. This case is not true for all the previous day of the storms. On few storm cases, we don't have EPBs presence in early storm nights. The EPBs occurrence is positively but weakly correlated $(+0.14)$ with solar $10.7 \mathrm{~cm}$ flux and it is negatively correlated (-0.07) with Ap indices. We found no-EPBs on many disturbed nights. However, we found EPBs occurrence on some nights despite magnetic activity as seen in bottom panel of Figure 6 (a). To understand the reason behind the EPBs suppression/occurrence during the magnetically disturbed nights, we have categorized all the disturbed nights as per Aarons [1991] criteria. Although we have used Ap index to identify the disturbed nights while Dst index is used to categorize storms.

Aarons [1991] proposed three simple relations of the ring current with the EPBs after analyzing several storm cases which can be summarized as follows: 1) if the maximum excursion of Dst takes place during daytime hours and well before sunset, the normal height rise of the $\mathrm{F}$ layer is disturbed and irregularities are inhibited that night (category 1);2) if the large excursion occurs in the midnight to post-midnight time period, the layer height rises and then falls and creates irregularities (category2); 3) if the large excursion of Dst takes place after sunset and before midnight, the layer height rise is not disturbed and irregularities form as on an undisturbed night (category 3 ). These three categories are redrawn for our observation nights as shown in Figure 6 (b). The time of the maximum Dst excursion is shown as cyan colored bars in all the panels. The horizontal bars in magenta color depicts the occurrence of EPBs. Here, in the Category I (Top Panel) first maximum excursion of Dst took place during daytime hours (10 to 16 LT) on the night of 11-12 March 2011. We note that EPBs are inhibited on the night which satisfies category I.
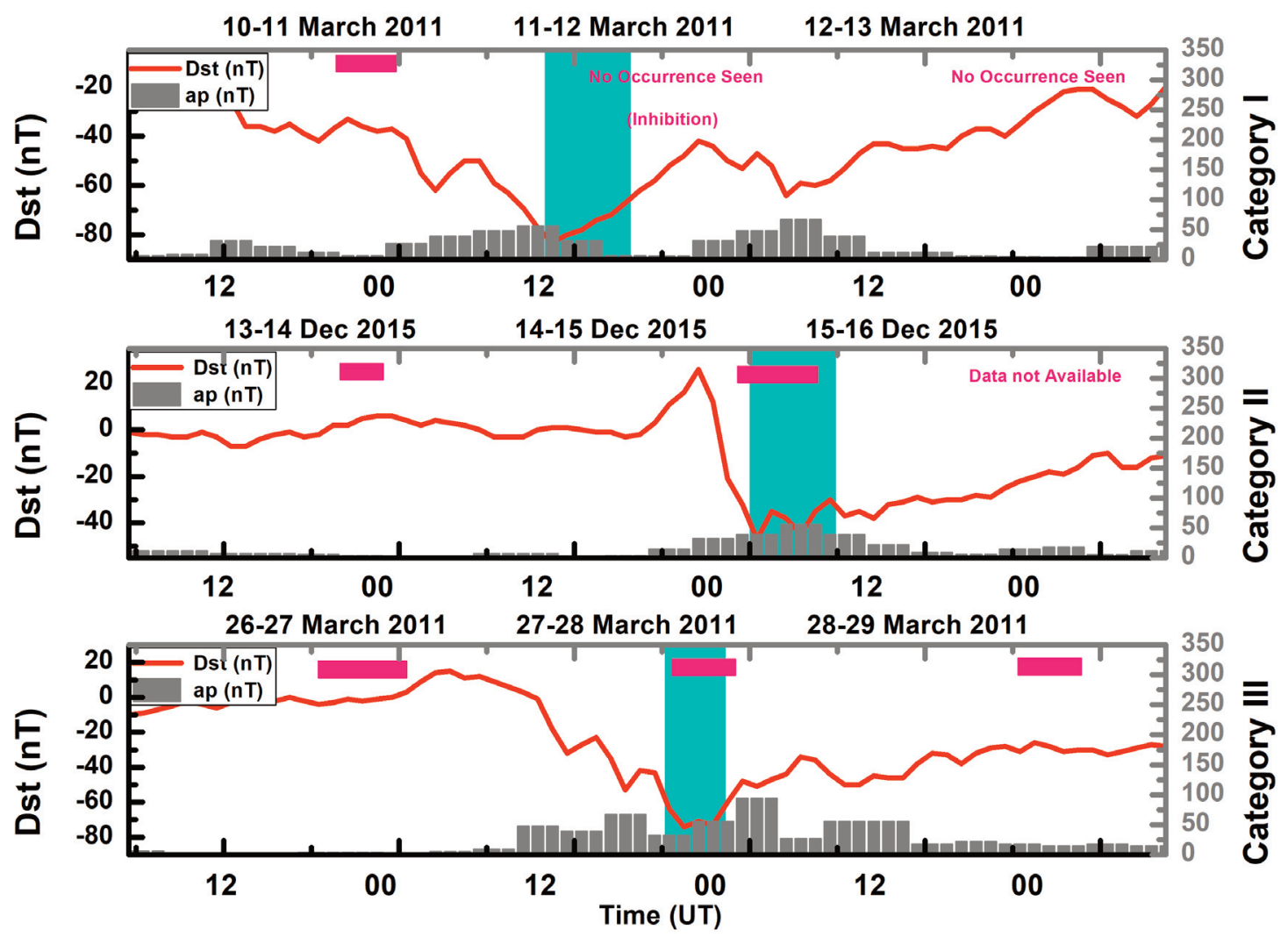

Figure 6 (b). Categories of effect of magnetic activity on occurrence of EPBs (as proposed in Aarons 1991). Category I (Top Panel): If the maximum excursion of Dst takes place during daytime hours (10 to 16 LT) then there is inhibition in irregularities (EPBs). Category II (Middle Panel): If the large excursion of Dst occurs in the midnight to postmidnight time period (00 to $06 \mathrm{LT}$ ) then there is generation in irregularities (EPBs). Category III (Bottom Panel): If the large excursion of Dst takes place after sunset and before midnight (i.e. 18 to 22 LT) then there is no effect on irregularity (EPB) occurrence. The grey colored bar denotes the hourly ap index for respective nights. 


\section{Onkar B. Gurav et al.}

On the other hand we have seen occurrence of EPBs on previous night. It is noted that, in the upper panel of Figure 6 (b), Dst minima is seen as low as - 80 nT. Further in Category II (Middle Panel), the large excursion of Dst occurs in the midnight to post-midnight time period (00 to $06 \mathrm{LT}$ ). Here we observe the generation in irregularities (EPBs) from post-midnight to the dawn periods. And hence this night satisfy category II. In Category III (Bottom Panel), the large excursion of Dst takes place after sunset and before midnight (i.e. 18 to $22 \mathrm{LT}$ ) then there is no effect on irregularity (EPBs) occurrence.

Geomagnetic disturbances are usually characterized by geomagnetic indices such as AP/Kp/AE/Dst. The most commonly used parameter for low latitude is the Dst index. The Dst index can be treated as a good measure of the overall strength of the near-Earth electric currents, especially the ring current. It is acquired from designated geomagnetic observatories operational at equatorial regions. We have measured the hourly Dst indices for the previous night, storm night and later night and measured the maximum Dst excursion time as shown in Table 4.

\begin{tabular}{|c|c|c|c|c|c|}
\hline Month & Date & $\begin{array}{l}\text { Total \# images } \\
\text { recorded in ASI }\end{array}$ & $\begin{array}{l}\text { \# of event } \\
\text { Images }\end{array}$ & $\begin{array}{l}\text { \% occurrenceof EPBs } \\
\text { from ASI }\end{array}$ & $\begin{array}{c}\text { \# TEC depletions } \\
\text { (>5 TECU) seen in } \\
\text { GPS data }\end{array}$ \\
\hline \multirow{13}{*}{ March } & 08-Mar & 96 & 0 & 0 & 0 \\
\hline & 09-Mar & 106 & 0 & 0 & 0 \\
\hline & 10-Mar & 132 & 0 & 0 & 0 \\
\hline & 11-Mar & 134 & 0 & 0 & 0 \\
\hline & 12-Mar & 132 & 0 & 0 & 0 \\
\hline & 13-Mar & 134 & 0 & 0 & 0 \\
\hline & 19-Mar & 44 & 0 & 0 & 0 \\
\hline & 20-Mar & 131 & 0 & 0 & 0 \\
\hline & 21-Mar & 134 & 0 & 0 & 0 \\
\hline & 22-Mar & 130 & 0 & 0 & 0 \\
\hline & 23-Mar & 84 & 0 & 0 & 0 \\
\hline & 24-Mar & 80 & 0 & 0 & 0 \\
\hline & 26-Mar & 57 & 0 & 0 & 0 \\
\hline Total & 13 & 1394 & 0 & 0 & 0 \\
\hline \multirow{17}{*}{ April } & 04-Apr & 68 & 0 & 0 & 0 \\
\hline & 09-Apr & 94 & 0 & 0 & 0 \\
\hline & 10-Apr & 72 & 0 & 0 & 0 \\
\hline & 11-Apr & 134 & 0 & 0 & 0 \\
\hline & 12-Apr & 134 & 0 & 0 & 0 \\
\hline & 13-Apr & 134 & 0 & 0 & 0 \\
\hline & 14-Apr & 134 & 0 & 0 & 0 \\
\hline & 15-Apr & 129 & 0 & 0 & 0 \\
\hline & 16-Apr & 108 & 0 & 0 & 0 \\
\hline & 17-Apr & 133 & 0 & 0 & 0 \\
\hline & 19-Apr & 134 & 0 & 0 & 0 \\
\hline & 20-Apr & 93 & 0 & 0 & 0 \\
\hline & 21-Apr & 106 & 0 & 0 & 0 \\
\hline & 22-Apr & 87 & 0 & 0 & 0 \\
\hline & 23-Apr & 69 & 0 & 0 & 0 \\
\hline & 24-Apr & 58 & 0 & 0 & 0 \\
\hline & 25-Apr & 40 & 0 & 0 & 0 \\
\hline Total & 17 & 1727 & 0 & 0 & 0 \\
\hline
\end{tabular}

Table 4. The summary of occurrence of EPBs inferred from ASI (Kolhapur) and GPS (Hyderabad) during observation nights in equinox months (March-April) of 2018. 
The maximum excursion time in Dst is a measure of maximum intensity of the globally symmetrical equatorial electrojet i.e. the "ring current". As per the Aarons [1991] criteria, we have categorized the disturbed nights into three categories using our observations by observing the time of Dst maximum excursion. The categories and corresponding \% occurrence of EPBs are depicted in Table 4.

In a nutshell, as per Aarons [1991] criteria the \% occurrence should be low or zero for category I due to expectations of EPB inhibition, whereas the \% occurrence should be high for category II due to expectation of EPB generation. We found that minority of storms which fall under category II supports Aarons [1991] criteria because on those storm nights the EPB occurrence has enhanced ( $>50 \%)$. It is known that in addition to Dst index, the interplanetary magnetic field (IMF) Bz also plays very important role in prompt penetration electric fields (PPEFs). The development of EPBs can be affected due to the geomagnetic disturbances and this is related to the variations in the zonal electric field strength near the equatorial regions that controls the vertical propagation of the F-layer. The related variations in the equatorial electric field strength due to geomagnetic activity can be classified into three phenomena, (1) prompt penetration of electric fields (PPEFs) i.e. "under-shielding effect" where EPBs are generated, (2) penetration electric fields (PEFs) i.e. "over-shielding" where EPBs are inhibited, and (3) the disturbance dynamo electric field (DDEF) which suppresses (enhances) the growth of EPBs in the post-sunset (postmidnight) sector [Carter et al., 2013 and references therein]. The PPEFs arises in the main-phase of a geomagnetic storm, which is described by the initial southward turning of IMF Bz. The PPEF is in the same direction as the quiettime electric field (i.e. eastward during the day and westward during the night) [e.g. Fejer et al., 2008], which results in stronger upward (downward) $\mathrm{E} \times \mathrm{B}$ plasma drift during the day (night) under magnetic disturbances. This can be termed as the "under-shielding effect". The EPB generation is supported by a stronger upward PRE just after the sunset hours, while the stronger downward drift in the post-midnight sector inhibits EPB generation [e.g., Sobral et al., 2002]. In the present study, we found occurrence of EPBs on 21 nights under magnetic disturbances (Table 4). From Table 4 we see that out of 22 nights only 06 nights (i.e. 27 \%) obeys Aaron's criteria. Few disturbed nights support the Aarons criteria but the large number of nights do not obey the same which needs detailed investigations.

\subsubsection{Hourly Averaged:}

In addition to daily averaged occurrence, the hourly variation in occurrence of EPBs on all the disturbed nights is also calculated as shown in Figure 6 (c). The blue background depicts zero occurrence. It is seen that the EPBs occurrence on magnetically disturbed nights shows different variation during increasing and decreasing phase of solar-cycle.

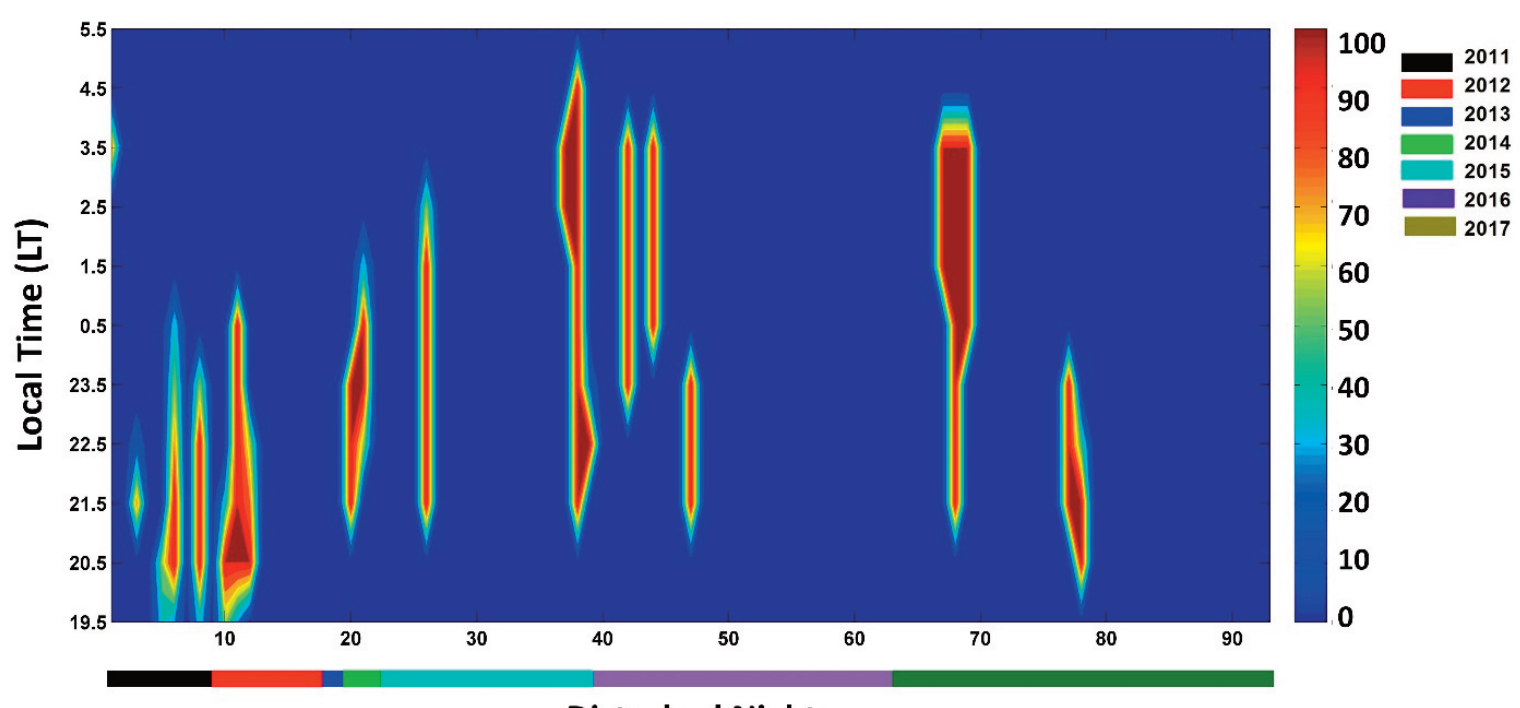

Disturbed Nights

Figure 6 (c). The hourly \% occurrence of EPBs on disturbed nights (Ap>18) for the period of 2011-2017. 


\section{Onkar B. Gurav et al.}

The occurrence of EPBs is confined around mid-night to after-midnight period (or well towards dawn period) during high or near solar maximum years (2014-2015). But during low solar activity years (2011 and 2018) the EPBs occurrence is confined to pre-midnight hours. Also, it is worthy to note that, the onset timings of EPBs goes on increasing towards solar maximum and further decreases towards solar minimum. This results are new and needs more clarification in future studies. Li et al. [2009] observed that, in the low-latitude regions, most EPB events begin at about 23:00 LT and retains for about $<45 \mathrm{~min}$. The greatest correlation between Kp and EPBs occurrence is found with an 8-9 h delay, a weak correlation exists for time delay of 6-7 h. From this scenario, they stated that over $3 \mathrm{~h}$ delayed disturbance dynamo electric fields-DDEF apparently inhibits the growth of EPBs in the early mid-night period. Carter et al. [2016] presented the occurrence of EPBs around the globe during 2015's St. Patrick's Day geomagnetic storm. They have used a network of 12 GPS receivers covering from South America to Southeast Asia, collocated VHF receivers at three stations and four nearby ionosondes. They reported that, following a burst of post-sunset EPB activity over India at the commencement of the storm owing to prompt penetration electric fields, EPB growth in the post-sunset sector across most longitudes was suppressed for 2 days. Most importantly, over the same period, they noted the enhancement in EPB growth in the post-midnight sector. Also, using a coupled thermosphere-ionosphere model they concluded that disturbance dynamo electric fields that took several hours to influence the equatorial region after the storm commencement were responsible for the suppression and growth of the post sunset and post-midnight EPBs, respectively. In present study, we found that, all the disturbed nights do not possess EPBs occurrence, further if the EPBs are encountered in magnetically disturbed nights then their occurrence varies with the phase of solar cycle.

\section{Pre mid-night post mid-night EPB occurrence}

Figure 7 indicates the pre mid-night versus post mid-night occurrence during quiet (to panel) as well as disturbed (bottom panel) nights during the period of 2011-2018. The EPB occurrence between 18:00 LT to 00:00 LT are counted as pre mid-night occurrence. The EPB occurrence between 00:00 LT to 06:00 LT are counted as post mid-night occurrence. We have just categorized all the nights as per these criteria and plotted as shown in Figure 7 .

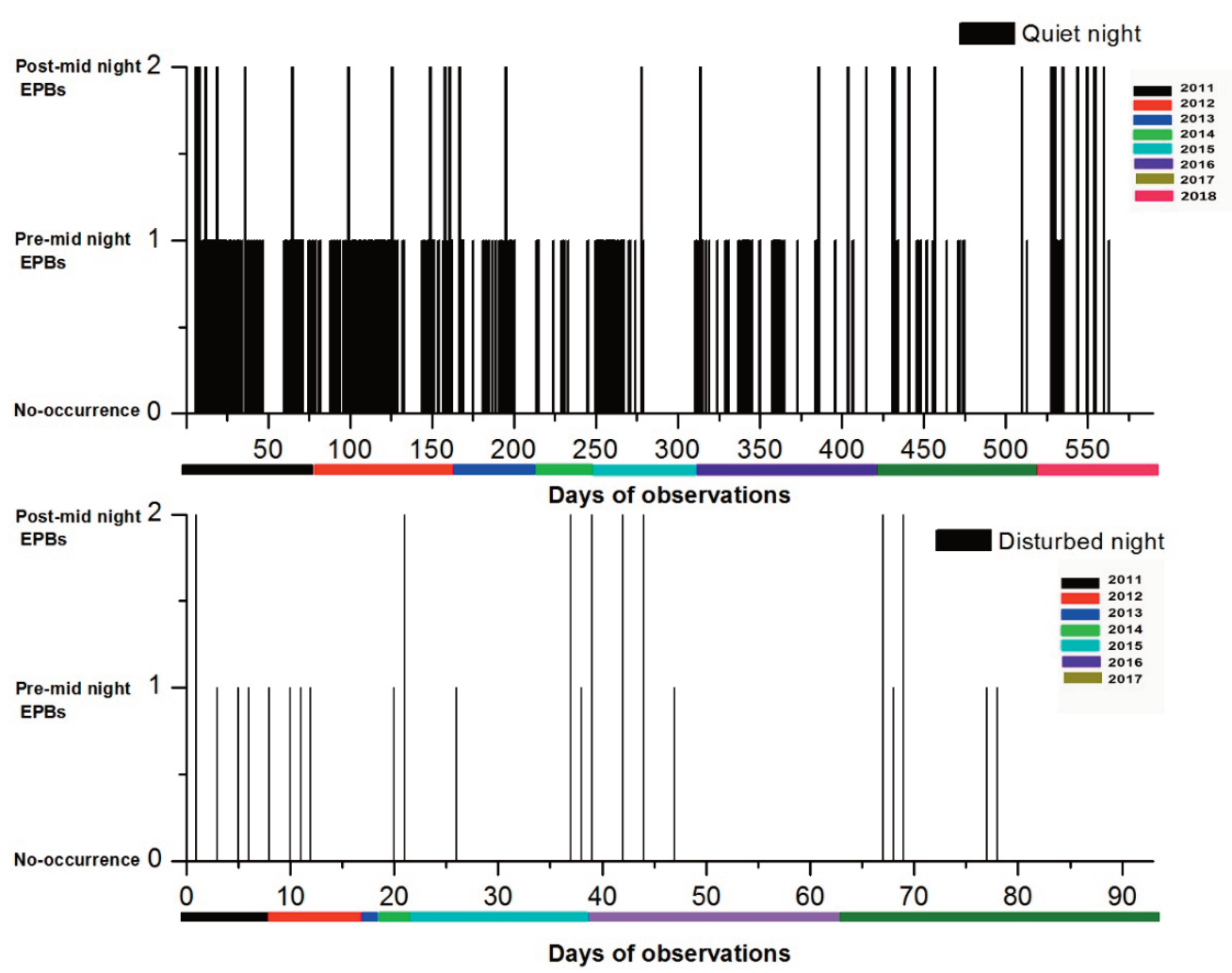

Figure 7. Pre versus post mid night EPB occurrence statistics for quiet as well as disturbed nights during 2011-2018. 


\section{Occurrence climatology of EPBs during solar cycle-24 in low latitude station, Kolhapur}

It is observed that, pre mid-night occurrence of EPBs is maximum in increasing phase as compared to decreasing phase of the solar cycle. But the case is different for post mid-night EPBs. Post mid-night EPBs are minimum during solar maximum years (2014-2015) and their occurrence is maximum towards solar minimum years. This suggests that post mid-night EPBs are expected during solar minimum period. Further, on the disturbed nights no significant variation is observed between pre and post mid-night EPB occurrence (bottom panel of Figure 7).

\section{Conclusions}

We have presented the statistical analysis of percentage occurrence of EPBs for about 683 nights of observations over Indian region, Kolhapur $\left(16.8^{\circ} \mathrm{N}, 74.2^{\circ} \mathrm{E}, 10.6^{\circ} \mathrm{dip}\right.$. Lat.) using the observations of All Sky Imager for the period of 2011-2018 that covers increasing and decreasing phases of the solar cycle-24. These observations correspond mostly to equinox/winter seasons and we don't have good observations during summer season due to the prevailing cloudy and rainy conditions in the summer. The important findings of this study can be highlighted as follows:

1) The EPBs on quiet nights occurs around 19:30 LT, peaks at or around mid-night and then its occurrence decreases towards remaining course of night. However, the onset timings are found to be delayed beyond 19:30 LT in solar minimum years.

2) It is seen that, the EPBs occurrence is higher during the ascending phase and comparatively lower in descending phase of the solar cycle. However, few disturbed nights show presence of EPBs and this occurrence is strongly dependent on the time of maximum Dst excursion as proposed by Aarons [1991].

3) The hourly occurrence of EPBs on disturbed night shows that the EPBs are restricted to pre-midnight sector in the low solar activity (LSA) period and are well spread towards dawn sector during the high solar activity (HAS) period. This peculiar feature could be linked to the $\mathrm{F}$ layer height rise at the equator. If height of $\mathrm{F}$ layer is very high in the high solar activity period, it may produce early and long duration spread F. But if F layer height didn't rise to very high altitudes during low solar activity period, it is possible that spread-F can be of short lived and also delayed. Also, the onset timings of EPBs on disturbed nights goes on increasing towards solar maximum but decreases towards solar minimum.

4) The EPBs occurrence during equinox months is found to be higher than winter months during ascending phase of solar cycle-24. Also, we unexpectedly observed the zero occurrence in equinox months during near solar minimum year.

5) The January, February, March and December are the only months where we can expect EPBs occurrence over Kolhapur in any year during solar cycle provided that during solar minimum the percentage of occurrence may be low.

6) During solar minimum years we found higher occurrence percentage of post mid-night EPBs.

Acknowledgements. OBG greatly acknowledge The Director, IIG Mumbai for financial support through Research Associate Scheme. The data presented in this work is obtained by the Indian Institute of Geomagnetism (IIG) with the support from the Department of Science and Technology (DST), Government of India. The All Sky Imager night-airglow observations were carried out under a scientific collaboration program between IIG and Shivaji University (SU), Kolhapur at MF RADAR Facility located in SU campus. The data of solar ( $10.7 \mathrm{~cm}$ flux) and geomagnetic indices (Ap index) were obtained from NOAA-GOES over the Internet (ftp.swpc.noaa.gov/pub/warehouse). The Dst and IMF Bz data were obtained from the OMNIWeb website (https://omniweb.gsfc.nasa.gov/form/omni_min.html).

\section{References}

Aarons, J. (1991). The role of the ring current in the generation or inhibition of equatorial F layer irregularities during magnetic storms, Radio Science, 26 (4), 1131-1149.

Abdu, M. A. (2012). Equatorial spread-F plasma bubble irregularities under storm time disturbance electric fields, J. Atmos. Sol. Terr. Phys., 75-76, 44-56.

Anderson, D. N. and Michael. Mendillo (1983). Ionospheric conditions affecting the evolution of equatorial plasma 


\section{Onkar B. Gurav et al.}

depletions, Geophys. Res. Lett., 10, 541-544.

Basu, S., Su. Basu, F. J. Rich, K. M. Groves, E. Mackenzie, C. Coker, P. R. Fagundes (2007). Response of the equatorial ionosphere at dusk to penetration electric fields during intense magnetic storms, J. of Geophys. Res. Space Phys., 112, 1-14.

Buhari, S. M., M. Abdullah, T. Yokoyama, Y. Otsuka, M. Nishioka, A.M. Hasbi, T. Tsugawa (2017). Climatology of successive equatorial plasma bubbles observed by GPS ROTI over Malaysia, J. of Geophys. Res. Space Phys., 1-11.

Carter, B. A., E. Yizengaw, R. Pradipta, J. M. Retterer, K. Groves, C. Valladares, K. Zhang (2016). Global equatorial plasma bubble occurrence during the 2015 St. Patrick's Day storm, J. of Geophys. Res. Space Phys., 894-905.

Carter, B. A., K. Zhang, R. Norman, V.V. Kumar, S. Kumar (2013). On the occurrence of equatorial F-region irregularities during solar minimum using radio occultation measurements, J. of Geophys. Res. Space Phys., 118, 892-904.

Chandra, H., S. Sharma., M. A. Abdu., \& I. S. Batista (2003). Spread-F at Anomaly Crest Regions in The Indian and American Longitudes, Advances in Space Research, 31, 717-727.

Chapagain, N. P., D. J. Fisher, J. W. Meriwether, J. L. Chau, \& J. J. Makela (2013). Comparison of zonal neutral winds with equatorial plasma bubble and plasma drift velocities, J. Geophys. Res.: Space Physics, 118 (4), 1802-1812.

Chatterjee, S. and S. K. Chakraborty (2013). Variability of ionospheric scintillation near the equatorial anomaly crest of the Indian zone, Ann. Geophys., 31, 697-711.

Das Gupta, A. Maitra, Santimay Basu (1981). Occurrence of nighttime VHF scintillations near the equatorial anomaly crest in the Indian sector, Radio Science., 16, 1455-1458.

Dabas, R. S., R. M. Das, K. Sharma, S. C. Garg, C. V. Devasia, K. S. Subbarao, V, Rao, P. V. S. R. (2007). Equatorial and low latitude spread-F irregularity characteristics over the Indian region and their prediction possibilities, Journal of atmospheric and solar terrestrial Physics, 69, 685-696.

Deng, B., J. Huang, W. Liu, J. Xu, \& L. Huang (2013). GPS scintillation and TEC depletion near the northern crest of equatorial anomaly over South China, Advances in Space Research, 51(3), 356-365.

Farley, D. T., E. Bonelli, B. G. Fejer, and M. F. Larsen (1986). The pre-reversal Enhancement of the Zonal Electric Field in the Equatorial Ionosphere, J.Geophys. Res., 91, 13723-13728.

Fejer, B. G. (1981), The equatorial ionospheric electric fields. A review. J. Atmo. Sol. Terr. Phys., 43, 377-386.

Fejer, B. G., J. W. Jensen, \& S. Su (2008). Seasonal and longitudinal dependence of equatorial disturbance vertical plasma drifts, Geophys. Res. Lett., 35, 2-5.

Ghodpage R. N., A. Taori, P. T. Patil, S. Gurubaran, S. Sripathi, S. Banola, A. K. Sharma (2014). Simultaneous optical measurements of equatorial plasma bubble (EPB) from Kolhapur $\left(16.81^{\circ} \mathrm{N}, 74.21^{\circ} \mathrm{E}\right)$ and Gadanki $\left(13.51^{\circ} \mathrm{N}\right.$, $79.21^{\circ}$ E), J. Atmo. Sol. Terr. Phys., 121, 196-205.

Ghodpage, R. N., P. T. Patil, O. B. Gurav, S. Gurubaran, \& A. K. Sharma (2018). Ionospheric response to major storm of $17^{\text {th }}$ March 2015 using multi-instrument data over low latitude station Kolhapur $\left(16.8^{\circ} \mathrm{N}, 74.2^{\circ} \mathrm{E}, 10.6^{\circ} \mathrm{dip}\right.$. Lat.), Advances in Space Research., 62 (3), 624-637.

Gonzalez, W. D., J. A. Joselyn, Y. Kamide, H. W. Kroehl, G. Rostoker, B.T. Tsurutani, \& V. M. Vasyliunas (1994). What is a geomagnetic storm? J. Geophys. Res., 99 (A4), 5771.

Gurav, O. B., A. K. Sharma, R. N. Ghodpage, D. P. Nade, G. A. Chavan, H. P. Gaikwad \& P.T. Patil (2018). Zonal drift velocity of Equatorial Plasma Bubbles during ascending phase of $24^{\text {th }}$ solar cycle using All Sky Imager over Kolhapur, India, J. Geophys. Res., Space Physics., 123, 10266- 10282.

Gurav, O. B., V. L. Narayanan, A. K. Sharma, R. N. Ghodpage, H. P. Gaikwad, P. T. Patil (2019). Airglow imaging observations of some evolutionary aspects of equatorial plasma bubbles from Indian sector, Adv. Space Res.., 64, 385-399.

Huang, C. Y., W. J. Burke, J. S. Machuzak, L. C. Gentile \& P. J. Sultan (2002). Equatorial plasma bubbles observed by DMSP satellites during a full solar cycle: Toward a global climatology, J. Geophys. Res., 107(A12), 1434.

Huang, C. (2011). Occurrence of Equatorial Plasma Bubbles during Intense Magnetic Storms, Int. J. Geophys., 2011, 1-10.

Kelley, M. C., J. J. Makela, W. E. Swartz, S. C. Collins, S. Thonnard, N. Aponte, \& C. A. Tepley (2000). Carribean ionosphere campaign, Year one: Airglow and plasma observations during two intense mid-latitude spread-F events, Geophys. Res. Lett., 27(18), 2825-2828.

Kumar, S., \& A. K. Gwal (2000). VHF ionospheric scintillations near the equatorial anomaly crest: Solar and magnetic activity effect, J. Atmos. Sol-Terr. Phy., 62(3), 157-167.

Li, G., B. Ning., L. Liu, W. Wan, and J. Y. Liu (2009). Effect of magnetic activity on plasma bubbles over equatorial and 


\section{Occurrence climatology of EPBs during solar cycle-24 in low latitude station, Kolhapur}

low-latitude regions in East Asia, Ann. Geophys., 27, 303-312.

Magdaleno, S., M. Herraiz, D. Altadill \& B. A. De Morena (2017). Climatology characterization of equatorial plasma bubbles using GPS data, J. Space Weather Space Clim., 7 (A3).

Makela, J. J., B. M. Ledvina, M. C. Kelley \& P. M. Kintner (2004). Analysis of the seasonal variations of equatorial plasma bubble occurrence observed from Haleakala, Hawaii, Annales Geophysicae, 22 (9), 3109-3121.

Maruyama, T., \& N. Matuura (1984). Longitudinal Variability of Annual Changes in Activity of Equatorial Spread F and Plasma Bubbles, 89 (A12), 10903- 10912.

Mendillo, M., J. Baumoardner, X. Pi \& P. J. Sultan (1992). Onset Conditions for Equatorial Spread F observations were made in August using the ALTAIR, J. Geophys. Res., 97, 13865-13876.

Mendillo, M., \& J. Baumgardner, M. Colerico, D. Nottingham (1997). Imaging science contributions to equatorial aeronomy: initial results from the MISETA program, J. Atmo. Sol. Terr. Phys., 59 (13), 1587-1599.

Mukherjee, G. K., and D. J. Shetti (2008). Plasma drifts motion in the F-region of the ionosphere using photometric night airglow measurements, Indian journal of radio and space physics, 37, 249-257.

Nade D. P., A. K. Sharma, S. S. Nikte P. T. Patil, R. N. Ghodpage, M. V. Rokade, S. Gurubaran, A. Taori and Y. Sahai (2013). Annales Geophysicae, 31, 2077-2084.

Nade, D. P., D.J. Shetti, A.K. Sharma, A. Taori, G.A. Chavan, P.T. Patil, R.N. Ghodpage, O.B. Gurav, S.S. Nikte (2015). Geographical analysis of equatorial plasma bubbles by GPS and nightglow measurements, Adv. Space Res., 56, 1901-1910.

Narayanan, V. L., S. Sau, S. Gurubaran, K. Shiokawa, N. Balan, K. Emperumal \& S. Sripathi (2014). A statistical study of satellite traces and evolution of equatorial spread F, Earth Planet \& Space, 66, 160.

Narayanan, V. L., S. Gurubaran, and K. Shiokawa (2016). Direct observational evidence for the merging of equatorial plasma bubbles. J. Geophys. Res. Space Physics., 121, 7923-7931.

Narayanan, V. L., A. K. Patra, S. Gurubaran, Chaitanya P. Pavan \& K. Emperumal (2019). Coincident airglow, VHF radar, and ionosonde observations of electrified medium-scale traveling ionospheric disturbances in the equatorial latitudes, Geophys. Res. Lett., 46, 7173-7181.

Patil, P. T., Ghodpage, R. N., Taori, A. K., Patil, R. P., Gurubaran, S., Nikte, S. N., Banola, S. (2016). The study of equatorial plasma bubble during January to April 2012 over Kolhapur (India). Ann. Geophys., 59, 2, A0214.

Rastogi, R. G., J. P. Mullen and E. Mackenzie. (1981). Effect of Geomagnetic Activity on Equatorial Radio VHF Scintillations and Spread F. J. Geophys. Res., 86, 3661-3664.

Ray, S., A. DasGupta, A. Paul, P. Banerjee (2003). Estimation of minimum separation of geostationary satellites for satellite-based augmentation system (SBAS) from equatorial ionospheric scintillation observations. The Journal of Navigation., 56 (1), 137-142.

Ray, S., and A. DasGupta (2007). Geostationary L-band signal scintillation observations near the crest of equatorial anomaly in the Indian zone. J. Atmo. Sol. Terr. Phys., 69(4-5), 500-514.

Sahai, Y., P. R. Fagundes, J. A. Bittencourt, M. A. Abdu (1998), Occurrence of large-scale equatorial F region plasma depletions during geomagnetic disturbances. J. of Atmo. Sol. Terr. Phys., 60, 1593-1604.

Sharma, A. K., Gurav, O. B., Chavan, G. A., Gaikwad, H. P., Ghodpage, R. N., \& Patil, P. T. (2017a). Variation in occurrence of equatorial plasma bubbles (EPBs) using All Sky Imager from low latitude station Kolhapur (16.8 ${ }^{\circ} \mathrm{N}, 74.2^{\circ} \mathrm{E}, 10.6^{\circ}$ dip. Lat.). Adv. Space Res., 60(11), 2452-2463.

Sharma, A. K., Chavan, G. A., Gaikwad, H. P., Gurav, O. B., Nade, D. P., Nikte, S. S., Ghodpage, R. N., Patil, P. T. (2017b). Study of ionospheric irregularities from Kolhapur (16.4 ${ }^{\circ}$ N, 74.2 ${ }^{\circ}$ E), J. Atmo. Sol. Terr. Phys., 169, 16-22.

Sharma, A. K., Gurav, O. B., Gaikwad, H. P., Chavan, G. A., Nade, D. P., Nikte, S. S., Patil, P. T. (2018). Study of equatorial plasma bubbles using all sky imager and scintillation technique from Kolhapur station: a case study. Astrophysics and Space Science, 363, 83.

Singh, R. P., Patel, R. P., \& Singh, A. K. (2004). Effect of solar and magnetic activity on VHF scintillations near the equatorial anomaly crest, Annales Geophysicae., 22, 2849-2860.

Sinha, H. S. S., R. N., Mishra, H., Chandra, Shikha Raizada, N. Dutt, and G. D. Vyas (1996), Multi-wavelength optical imaging of ionospheric plasma depletions. Indian J. Radio Space Phys., 25, 44-52.

Sinha, H. S. S., and S. Raizada (2000). Some new features of ionospheric plasma depletions over the Indian zone using all sky optical imaging. Earth Planets Space, 52, 549-559.

Sivakandan, M., Paulino, I., Ramkumar, T. K., Taori, A., Patra, A. K., Sripathi, S., Niranjan, K., A.V. Bilibio (2019). Multi-instrument investigation of troposphere-ionosphere coupling and the role of gravity waves in the 


\section{Onkar B. Gurav et al.}

formation of equatorial plasma bubble, Journal of Atmospheric and Solar-Terrestrial Physics, 189, 65-79.

Smith, J., and R. A. Heelis (2017), Equatorial plasma bubbles: Variations of occurrence and spatial scale in local time, longitude, season, and solar activity, J. Geophys. Res. Space Physics, 122, 5743- 5755.

Sripathi, S., M. A. Abdu, A. K. Patra, \& R. N. Ghodpage (2018). Unusual generation of localized EPB in the dawn sector triggered by a moderate geomagnetic storm. Journal of

Geophysical Research: Space Physics, 123, 9697- 9710.

Sripathi, S., R. Singh, S. Banola, S. Sreekumar, K. Emperumal, and C. Selvaraj (2016), Characteristics of the equatorial plasma drifts as obtained by using Canadian Doppler ionosonde over southern tip of India, J. Geophys. Res. Space Physics, 121, 8103- 8120 .

Sobral, J. H. A., M. A. Abdu, H. Takahashi, M. J. Taylor, E. R. de Paula, C. J. Zamlutti, M. G. de Aquino, and G. L. Borba (2002), Ionospheric plasma bubble climatology over Brazil based on 22 years (1977-1998) of $630 \mathrm{~nm}$ airglow observations, J. Atmos. Sol. Terr. Phys., 64, 1517-1524.

Sripathi, S., S. Banola, K. Emperumal, B. Suneel Kumar, \& S. M. Radicella (2018). The role of storm time electrodynamics in suppressing the equatorial plasma bubble development in the recovery phase of a geomagnetic storm. J. Geophys. Res.: Space Physics, 123, 2336-2350.

Sun, Y. Y., J. Y. Liu, \& C. H. Lin (2012). A statistical study of low latitude F region irregularities at Brazilian longitudinal sector response to geomagnetic storms during post-sunset hours in solar cycle 23, 117, 1-13.

Sun, L., J. Xu, W. Wang, W. Yuan, Q. Li, \& C. Jiang (2016). A statistical analysis of equatorial plasma bubble structures based on an all-sky airglow imager network in China. J. Geophys. Res.: Space Physics, 121(11), 11495-11517.

Taori, A., A. K. Patra, \& L. M. Joshi (2011). Gravity wave seeding of equatorial plasma bubbles: An investigation with simultaneous F region, E region, and middle atmospheric measurements. J. Geophys. Res.: Space Physics, 116 (5), A05310.

Taori, A., N. Parihar, R. Ghodpage, N. Dashora, S. Sripathi, E. A. Kherani, and P. T. Patil (2015). Probing the possible trigger mechanisms of an equatorial plasma bubble event based on multistation optical data, J. Geophys. Res.: Space Physics, 120, 8835-8847.

Tsunoda, R. T. (1985). Control of the seasonal and longitudinal occurrence of equatorial scintillations by the longitudinal gradient in integrated region Pedersen conductivity. J. Geophys. Res.., 90, 447-456.

Taori A., A. Jayaraman and V. Kamalakar (2013), Imaging of mesosphere-thermosphere airglow emissions over Gadanki (13.51N, 79.21E): first results. J. Atmos. Terr. Phys., 93, 21-28.

Vyas, B. M., \& B. Dayanandan (2011). Nighttime VHF ionospheric scintillation characteristics near the crest of Appleton anomaly station, Udaipur $\left(24.6^{\circ} \mathrm{N}, 73.7^{\circ} \mathrm{E}\right)$. Indian Journal of Radio and Space Physics, 40 (4), 191-202.

Wiens, R. H., B. M. Ledvina, P. M. Kintner, M. Afewerki, \& Z. Mulugheta (2006). Equatorial plasma bubbles in the ionosphere over Eritrea: occurrence and drift speed, Annales Geophysicae., 24, 1443-1453.

Xiong, C., J. Park, H. Luhr, C. Stolle, and S. Y. Ma (2010). Comparing plasma bubble occurrence rates at CHAMP and GRACE altitudes during high and low solar activity. Ann. Geophys., 28, 1647-1658.

*CORRESPONDING AUTHOR: Rupesh GHODPAGE,

Medium Frequency Radar, Indian Institute of Geomagnetism,

Shivaji University Campus, Kolhapur, India

e-mail: rupeshghodpage@gmail.com

(c) 2020 the Istituto Nazionale di Geofisica e Vulcanologia.

All rights reserved 